\title{
Música, rituales y mundos de sentido. El rol del refuerzo multimodal en la producción de emociones en tres confesiones religiosas en Bogotá
}

\author{
Music, rituals and worlds of sense. The role of multimodal \\ reinforcement in the production of emotions in three religious \\ confessions in Bogotá
}

\author{
por \\ Óscar Hernández Salgar \\ Departamento de Música, Pontificia \\ Universidad Javeriana, Colombia \\ oscar.hernandez@javeriana.edu.co \\ Juan Daniel Gómez Rojas \\ Departamento de Psicología, Pontificia \\ Universidad Javeriana, Colombia \\ jd.gomez@javeriana.edu.co \\ Luis Gabriel Mesa Martínez \\ Departamento de Música, Pontificia \\ Universidad Javeriana, Colombia \\ luis.mesa@javeriana.edu.co. \\ Luis Fernando Valencia Rueda \\ Departamento de Música, Pontificia \\ Universidad Javeriana, Colombia \\ valencia.luis@javeriana.edu.co \\ Diego Alberto Gómez Nieto \\ Fundación Universitaria Juan N. Corpas, \\ Colombia \\ diego.gomez@juanncorpas.edu.co \\ María Camila Mendoza Castro \\ Departamento de Música, Pontificia \\ Universidad Javeriana, Colombia \\ mmendozac@javeriana.edu.co \\ Laura Rocío Molina Bohórquez \\ Universidad Nacional Autónoma de \\ México, México \\ lauralalu1892@gmail.com \\ Julio César Guevara Prieto \\ Orquesta Filarmónica de Bogotá, \\ Colombia \\ juceguep@hotmail.com
}

Este artículo explora el papel de la música, en combinación con otros modos de expresión, en la producción de emociones en rituales de tres distintas confesiones religiosas en Bogotá. La investigación realizada buscó probar la propuesta teórica de los "mundos de sentido", según esta, una mayor coincidencia entre los contenidos de diferentes lenguajes significantes produce mayor intensidad emocional además de delimitar las posibilidades de acción. Para ello se hicieron entrevistas y cuestionarios, se analizó el material expresivo en cada ritual y se midió la respuesta emocional de nueve sujetos mediante el comportamiento físico y medidas electroencefalográficas. El análisis permite concluir que el ritual con menor predictibilidad y mayor concordancia entre la música y otros elementos significantes es también el ritual en el que se expresan las emociones con mayor intensidad y se siguen de forma más 
rigurosa los mandatos de la confesión, mientras que los rituales con estructuras predecibles y mayor contradicción entre modos muestran menor intensidad emocional y un menor nivel de obediencia. Sin embargo, es imposible establecer una relación de causalidad entre el material expresivo y la respuesta emocional. Hacia el final del artículo se proponen otras líneas de indagación para examinar el potencial de la música en la orientación de la acción como parte de experiencias de refuerzo multimodal.

Palabras clave: Emociones musicales, emociones religiosas, refuerzo multimodal, mundos de sentido, musicología empírica.

This article explores the role of music, along with other modes of expression, in the production of emotion in three distinct religious rituals in Bogotá. The research sought to prove the theoretical concept of "worlds of sense," within which greater correlation between the contents of different signifying languages not only produces greater emotional intensity but also delineates what behaviors are possible. To accomplish this, interviews and questionnaires were completed, the expressive material of each ritual was analyzed, and the emotional response of nine subjects was measured through physical behavior and electro-encephalographic measurements. The analysis allowed us to conclude that the ritual with less predictability and greater concordance between music and other significant elements is also the ritual in which emotions are expressed with greater intensity and the mandates of the church/mosque are followed more rigorously, while rituals with predictable structures and greater contradiction between the musical and other key elements show less emotional intensity and a lower level of obedience. However, it is impossible to establish a direct causal relationship between the expressive material and the emotional response. Towards the end of the article, other lines of inquiry are proposed to examine the potential of music to influence behavior in the context of multimodal reinforcement experiences.

Keywords: Musical emotions, religious emotions, multimodal reinforcement, worlds of sense, empirical musicology.

\section{INTRODUCCIÓN ${ }^{1}$}

Este artículo se desprende de un interés investigativo de más largo plazo que busca estudiar la relación entre música y poder, y más exactamente el papel del sonido en la orientación de la acción humana en combinación con otros modos de lenguaje; especialmente aquellos de tipo no verbal ${ }^{2}$. Para ello partimos del concepto de "mundo de sentido", entendido como una forma de experiencia multimodal en la que distintos modos (sonoro, visual, táctil, discursivo verbal, etc.) expresan contenidos que se refuerzan unos a otros, dando como resultado una inmersión totalizante que puede llegar a establecer marcos para la acción del sujeto (Hernández 2016: 58). El concepto de mundo de sentido permitiría entonces explicar el papel de la música en la orientación de la acción dentro de un marco experiencial determinado, desde una perspectiva que vincula varias disciplinas (semiótica musical, psicología, ciencias de la cognición, etnomusicología). Antes de esta investigación no se había realizado un trabajo de campo que permitiera validar este concepto mediante la observación y análisis de experiencias con oyentes reales. Por ello, uno de los principales

1 Este artículo se desprende del proyecto de investigación "Música, rituales y mundos de sentido”, financiado por la Pontificia Universidad Javeriana. El presente texto hace énfasis en el análisis cualitativo y en aspectos musicológicos. En otro artículo se presentará el análisis psicomusicológico detallado, con más énfasis en la información cuantitativa. Por ello esta información solo se presenta aquí de forma resumida para facilitar la lectura.

2 Para efectos de este proyecto entendemos, de acuerdo con Michel Foucault, que "Lo que define una relación de poder es que es un modo de acción que no actúa de manera directa e inmediata sobre los otros, sino que actúa sobre sus acciones: una acción sobre la acción, sobre acciones eventuales o actuales, presentes o futuras" (Foucault 1988: 14). En ese sentido, entendemos que la construcción de marcos para la delimitación de la acción por medio de lenguajes no verbales es en sí misma un ejercicio de poder, sin necesidad de que dicha delimitación sea atribuible a un agente específico. 
propósitos del proyecto consistió en poner a prueba algunos de los supuestos que subyacen a la noción de mundo de sentido: en primer lugar, la idea de que diferentes modos de lenguaje pueden reforzar contenidos similares o contradecirse; en segundo lugar, la idea de que el refuerzo multimodal puede incidir en el aumento de la intensidad emocional; y, en tercer lugar, la idea de que una vivencia emocional intensa y colectiva, dada como fruto de una experiencia de refuerzo multimodal, establece unos marcos que naturalizan los comportamientos posibles en dicha experiencia. Para ello se hicieron entrevistas, cuestionarios, observaciones y mediciones electroencefalográficas en rituales de tres confesiones religiosas diferentes en Bogotá3.

\section{ENFOQUE TEÓRICO}

Retomando la teoría James-Lange, Antonio Damasio (2007) plantea que las emociones no son la causa de una respuesta corporal, sino que, por el contrario, la respuesta fisiológica a un estímulo es mapeada por el cerebro para dar lugar a los estados que conocemos como emociones. Esto sugiere que una emoción puede ser inducida en la medida en que el sujeto se exponga a estímulos que favorezcan los comportamientos corporales normalmente asociados a esta. Este último punto está relacionado con un tópico que se ha vuelto recurrente en la teoría social contemporánea, y tiene que ver con la circularidad de la emergencia del yo. Tanto Louis Althusser (1970) como Slavoj Žižek (2003) y Judith Butler (2001) hacen referencia a la famosa frase de Pascal: "actúa como si creyeras, ora, arrodíllate y creerás, la fe vendrá por sí sola” (citado en Žižek 2003: 21), para dar cuenta del carácter performativo de la identidad. La idea que subyace a este llamado es que el sujeto emerge a partir de la interpelación, pero este mismo acto es posible porque el sujeto de alguna manera también preexiste a la interpelación. Para el caso de la experiencia religiosa de la que habla Pascal, esto mismo se puede refrasear en los términos de Žižek: "arrodíllate y creerás que te arrodillaste a causa de tu creencia; o sea, respetar el ritual es una expresión/efecto de tu creencia interna; en resumen, el ritual "externo" genera performativamente su propio fundamento ideológico" (2003).

Asimismo, de acuerdo con Damasio, el comportamiento de obediencia al ritual generaría un estado corporal, que a su vez es interpretado por el cerebro, no solo como una actitud adecuada para el contexto, sino como algo anclado en experiencias y expectativas previas al ritual (gracias a procesos anteriores de categorización). En otras palabras, si se tiene en cuenta la circularidad del yo explicada desde la filosofía, más la idea de que la respuesta corporal precede a los sentimientos, se puede sugerir que tanto la actitud recogida de un ritual católico o musulmán como la actitud enérgica de un culto pentecostal pueden ser interpretados por el sujeto como causados por la fe, aunque en principio se originen en, o sean favorecidos por, respuestas a estímulos concretos del entorno ${ }^{4}$.

3 La selección de experiencias en el marco de rituales religiosos (católicos, pentecostales, musulmanes), obedece a que estos espacios constituyen un entorno privilegiado para la observación de relaciones entre distintos elementos significantes porque: 1) tienen un marco temporal delimitado y suceden periódicamente, 2) se dan en un espacio con elementos previamente configurados, 3) siguen un guion, 4) asignan a la música o al sonido una función determinada dentro del ritual, 5) tienen un público asiduo, y 6) aunque los rituales de diferentes confesiones tienen aspectos en común, existe un gran margen para la diferencia en las formas en que se relacionan los distintos elementos significantes, lo que permite hacer comparaciones pertinentes para un estudio como este.

4 Lo anterior no quiere decir que las experiencias religiosas sean "falsas", o que la emoción religiosa se reduzca a una manipulación. Sin embargo, sí es posible pensar que muchos de los actos 
En este sentido, acudimos al concepto de mundo de sentido, para abordar el análisis de la expresión emocional de diferentes modos de lenguaje en unas experiencias concretas de ritual. Este concepto parte de la idea de que, en cualquier experiencia humana, los elementos significantes de diferentes modos pueden contradecir sus contenidos o reforzarlos recíprocamente para potenciar una expresión emocional similar. Existe una producción importante alrededor de la relación entre música y emociones ${ }^{5}$, y dentro de esta es muy común la que trata de establecer relaciones directas entre estructuras sonoras y emociones ${ }^{6}$. Sin embargo, una de las conclusiones más frecuentes es la de que ningún elemento musical considerado de manera aislada es suficiente para provocar una respuesta emocional específica.

Thomas Turino plantea el concepto de "densidad semiótica", según este, las diferentes capas significantes del tejido musical pueden tener relaciones de coincidencia o contradicción (Turino 2014: 189). Pero no hemos encontrado muchos estudios que expandan esta noción más allá del material sonoro para examinar la relación de refuerzo o contradicción entre la música y otros modos. Como antecedentes de refuerzo multimodal se pueden mencionar estudios como el de Meier, Robinson y Clore (2004) que relaciona el nivel de brillo con la categorización emocional de diferentes palabras, o el de Sollberge, Rebe y Eckstein (2003) que evaluó la velocidad en categorización emocional de acordes que eran acompañados por estímulos visuales. Según Hanser y Mark (2013), estos y otros estudios muestran que un modo puede influenciar la percepción de otro de acuerdo con la coincidencia en su contenido emocional. En esta misma línea se encuentra el concepto de "musical fit" o ajuste musical propuesto por North y Hargreaves (2008), según este, la música puede estar asociada a un producto, o a los valores que este representa, facilitando el proceso de compra.

En cuanto a los mecanismos por los que se pueden reforzar contenidos entre diferentes modos de lenguaje, el referente más importante para esta investigación es la teoría del sistema simulador de Lawrence Barsalou (2009), según esta, cualquier proceso de conceptualización pasa por la integración de información multimodal sobre la base de experiencias repetidas. A partir de esta información almacenada, un estímulo relacionado puede disparar simulaciones, es decir, reactivaciones parciales de las respuestas aprendidas, que incluyen componentes emocionales. Así, las asociaciones experimentadas reiteradamente pueden producir expectativas de ciertos tipos de relación entre contenidos modales diferentes que, al presentarse en la experiencia, son vividas como un refuerzo de contenidos similares.

Asimismo, desde la teoría social el concepto de mundo es abordado por Maurizio Lazzarato (2006), quien afirma que las sociedades de control se caracterizan por una sobreoferta de "mundos" preconstituidos y normalizados, ejemplificados principalmente en la comunicación publicitaria. Para Lazzarato, estos "agenciamientos de enunciación y regímenes de signos" constituyen una "solicitación para adoptar una forma de vida" y por ello producen la sensación de que "una vez todo es posible (dentro de las alternativas

atribuidos a la fe pueden ser al menos propiciados por lo que Damasio llama estímulos emocionalmente competentes (EEC).

5 En los últimos años han proliferado los estudios desde la psicología de la música y las ciencias de la cognición musical que relacionan la música con las emociones (Sloboda y Juslin 2010; Krumhansl 2002; Collier 2007; Keller y Schubert 2011; Gabrielsson y Lindström 2010; Zbikowski 2010), y también existen estudios que abordan dicha relación en el caso específico de las celebraciones religiosas (Rouget 1985; Becker 2004; Penman y Becker 2009; Miller y Strongman 2002, Gridley y Hoff 2011; Guerra 2009). Sin embargo, estas investigaciones no establecen una relación explícita entre el estímulo sonoro y otros modos de lenguaje para aproximarse a la constitución de dispositivos que orientan la acción.

6 Ver Gabrielsson y Lindström 2010. 
preestablecidas), ya nada es posible (la creación de algo nuevo)" (Lazzarato 2006: 102-103). $\mathrm{Al}$ conectar esta noción con los referentes mencionados de psicología y ciencias cognitivas, es posible hipotetizar que, en estos casos, el refuerzo entre modos puede potenciar el carácter totalizante de la experiencia, produciendo unos marcos que naturalizan las posibilidades de acción, es decir un mundo de sentido (Hernández 2016: 58).

Para evaluar si los rituales religiosos pueden producir efectos similares a los que se esperan de un mundo de sentido, fue necesario adoptar un abordaje transdisciplinar que permitiera tener información como mínimo acerca de la naturaleza y contenido del material significante, la respuesta emocional de los sujetos y el contexto institucional de cada una de las confesiones: la Iglesia Pentecostal Unida de Colombia (IPUC), la Iglesia de San Alfonso María Ligorio, y la Mezquita Estambul, todas en Bogotá. Para el estudio se utilizó una estrategia mixta de investigación con alcance descriptivo en donde los datos cualitativos fueron recogidos mediante entrevistas a profundidad a los líderes de cada ritual y a los feligreses que asistieron a los cultos ${ }^{7}$. Los datos cuantitativos fueron capturados por medio de cuestionarios -antes y después del ritual- y mediante la utilización de registros electroencefalográficos de la actividad cerebral de tres sujetos por cada ritual a lo largo de la duración de este ${ }^{8}$. Aquí se trabajó con un enfoque dimensional que evaluó la valencia (positividad o negatividad) y la actividad (arousal) de las respuestas emocionales, según el modelo circunflejo de Russell ${ }^{9}$. Posteriormente se hizo un análisis del material significante

7 En cuanto a la técnica de selección de la muestra, no se cuenta con información previa acerca de la población, que permita reconocer el comportamiento de las variables estudiadas en términos de su ajuste a la normalidad o varianza. Ello hace que sea imposible determinar la probabilidad que tiene cada uno de los elementos de la población de ser incluida en la muestra. En este sentido se hizo un muestreo no probabilístico y más precisamente un muestreo intencional o de conveniencia (Hernández, Fernández y Baptista 2010). Para las entrevistas se contó con un protocolo de administración que indagaba por el perfil demográfico, gustos musicales, formación musical, contextos de escucha y experiencias religiosas con música, entre otros aspectos. Todas las entrevistas fueron transcritas para su análisis.

8 El sistema de registro electroencefalográfico utilizado en el estudio es un dispositivo Emotiv EPOC, un sistema de conexión cerebro-computador que utiliza un casco de adquisición de datos de onda cerebral para detectar estados mentales ligados a la actividad cerebral y los envía de manera inalámbrica al computador. Tiene catorce sensores de alta resolución equipados con filtro de señal especializado que se localizan según el sistema internacional de posicionamiento 10-20: AF3, F7, F3, FC5, T7, P7, O1, O2, P8, T8, FC6, F4, F8, AF4. Con la distribución global que tienen estos puntos de registro es posible realizar un mapeo cerebral de la actividad de un individuo y mediante algoritmos especializados de análisis y filtración de señales de ruido se extraen los perfiles cognitivos y afectivos asociados a los datos EEG capturados por el dispositivo.

Para hacer los registros de asimetría cerebral se instaló adecuadamente el dispositivo de adquisición de datos Emotiv EPOC en el cuero cabelludo del participante en la investigación. Se capturó la actividad electroencefalográfica de los puntos F3 y F4 a una tasa de muestreo de 128 datos por segundo. A los datos les fueron aplicados algoritmos computacionales especializados para filtrarlos de errores de artefacto y luego fueron procesados utilizando una aplicación de MatLab desarrollada específicamente para extraer, mediante transformada rápida de Fourier (TRF), la magnitud de los componentes de onda cerebral característicos (delta, theta, alfa, beta y gamma). La selección de los sujetos para el registro electroencefalográfico buscó tener homogeneidad en las siguientes variables: años de asistencia al culto respectivo, edad, género, nivel educativo, nivel socioeconómico. Todos los sujetos firmaron un consentimiento informado, aprobado previamente por el Comité de Investigación y Ética de la Facultad de Artes.

9 Los estudios referentes a emoción basados en el conocimiento de la actividad cerebral, siguiendo el modelo circunflejo de Russell, toman como dimensiones principales de análisis de la emoción a la valencia y a la excitabilidad cerebral, denominada con el término en inglés "arousal" (Mauss \& Robinson 
a lo largo del ritual (elementos musicales, sonoros, visuales y kinestésicos) y se contrastó con la respuesta emocional de los sujetos basado en la selección de veintitrés momentos clave del ritual (veinticuatro en el caso de la mezquita) ${ }^{10}$. Es importante aclarar que ninguno de los miembros del equipo de investigación había participado anteriormente en los cultos observados. A continuación se describe el análisis realizado con cada ritual.

\section{MISA DE PEREGRINACIÓN EN LA IGLESIA DE SAN ALFONSO MARÍA DE LIGORIO}

En la parroquia San Alfonso María de Ligorio, dirigida por la Congregación del Santísimo Redentor, se sigue el Rito Romano en su Forma Ordinaria11, con sus cuatro momentos:

2009; Russell, 1980). Los estudios electrofisiológicos de la valencia y de sus marcadores observables en la actividad cerebral fueron iniciados por Richard J. Davidson y Jeffrey B. Henriques (Davidson 1995; Henriques \& Davidson 1990, 1991), quienes establecieron que los individuos con depresión y estados afectivos negativos tienen una asimetría cortical frontal característica en comparación con la actividad electroencefalográfica de grupos control conformados por individuos sin depresión y estados afectivos neutros o positivos. En los grupos control hay una tendencia a que se produzca la misma cantidad de activación cortical frontal en los hemisferios izquierdo y derecho, o incluso más actividad en el hemisferio izquierdo, pero en los individuos con depresión hay una disminución de la actividad cortical del hemisferio izquierdo y una actividad mayor en el hemisferio derecho. Esta condición electrofisiológica en la depresión correlaciona con un predominio del componente alfa de las ondas cerebrales en áreas frontales de la corteza izquierda y una disminución del poder de este mismo componente en el lóbulo frontal derecho, razón por la que se ha considerado esta asimetría con predominio de la onda alfa en el hemisferio izquierdo como un marcador electrofisiológico característico de la depresión y desde un punto de vista no patológico, de los estados de afecto negativo asociados a la tristeza. Se asume de esta manera que los estados emocionales positivos están caracterizados por una asimetría de actividad cerebral con predominio de actividad alfa en el lóbulo frontal derecho y una mayor actividad cortical caracterizada por ondas beta en el lóbulo frontal izquierdo.

En los estudios de Davidson la asimetría en la activación fue medida por el poder del componente alfa (8-12 Hz) de la onda cerebral registrada en los puntos F3 y F4 del Sistema Internacional de Registro Electroencefalográfico (Rosenfeld y Baehr 2003; Baehr, Rosenfeld, Baehr y Earnest 1998). Se han usado dos fórmulas para calcular el coeficiente de asimetría alfa:

$$
\begin{aligned}
& \mathrm{A}[1]=\log \mathrm{D}-\log \mathrm{I} \\
& \mathrm{A}[2]=(\mathrm{D}-\mathrm{I}) /(\mathrm{D}+\mathrm{I})
\end{aligned}
$$

donde $\mathrm{D}$ corresponde a la magnitud de alfa registrada en el punto F4 localizado en la corteza frontal del hemisferio derecho e I corresponde a la magnitud de alfa registrada en el punto F3 localizado en la corteza frontal del hemisferio izquierdo. Aunque las dos fórmulas no son matemáticamente equivalentes, hay una correlación entre ellas cercana a 0,98 (Baehr, Rosenfeld, Baehr y Earnest 1998). Entre más positivo $(\mathrm{A}>0)$ es el valor de este indicador hay mayor actividad en la corteza frontal izquierda y además el afecto es más positivo; por otro lado, cuando el indicador es cercano o menor a cero hay menor actividad en la corteza frontal izquierda y el afecto característico está asociado a la depresión. En el presente estudio se aplicó la segunda fórmula para calcular el coeficiente de asimetría. Por otra parte, para la medición del nivel de excitación cortical y alertamiento (arousal) se tomó el registro del componente beta de alta frecuencia $(18-30 \mathrm{hz})$ en los puntos T7 y T8, siguiendo la propuesta teórica de Kapp, Supple y Whalen (1994), quienes encontraron que el arousal de los mamíferos es influido por la actividad del núcleo central amigdaloide que se encuentra localizado en las áreas temporales del cerebro. El valor instantáneo de arousal en cada momento del análisis es calculado promediando la actividad beta de alta frecuencia de los puntos T7 y $\mathrm{T} 8$.

10 En el análisis, los momentos escogidos para cada ritual se identifican con la nomenclatura m1, m2, m3, etc. Los sujetos, por otro lado, se identifican con una letra mayúscula diferente para cada confesión y un número así: Mezquita Estambul (I1, I2, I3), Iglesia de San Alfonso (C1, C2, C3), IPUC (P1, P2, P3).

11 De acuerdo con el Novus Ordo Missae de 1969, celebrado en español. 
1) Ritos iniciales, 2) Liturgia de la palabra, 3) Liturgia de la Eucaristía y 4) Ritos de despedida. En esta parroquia se hace todos los días 14 de cada mes una misa de peregrinación por el Señor de los Milagros de Buga. Esta misa tiene una sección adicional en donde se realizan unos gozos y peticiones al Señor de los Milagros, al final de la liturgia de la palabra ${ }^{12}$. Como parte del trabajo etnográfico, se hizo una observación de la misa del 14 de junio de 2016 que se desarrolló como se indica en la Tabla 1 (ver Tabla 1).

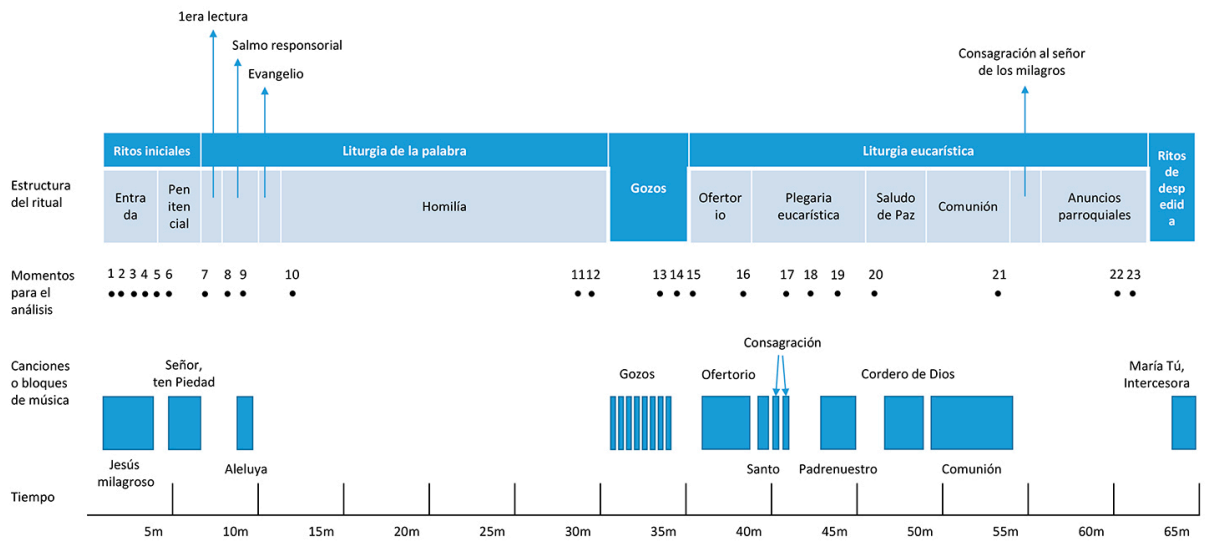

Tabla 1: Estructura del rito de la Iglesia de San Alfonso.

Respecto de las características espaciales del templo, este solo tiene unas décadas de antigüedad, pero contiene gran parte de los retablos y cuadros del antiguo templo colonial de Santa Inés de Montepulciano; así, con arquitectura moderna, y ornamentación del barroco colonial, presenta un cuadro que une varias temporalidades y estéticas ${ }^{13}$. Su interior se adorna con colores dorados y rojizos y las ventanas laterales presentan mosaicos de vitrales que evocan escenas bíblicas. El cielorraso sostiene una serie de seis lámparas en estilo rococó apagadas que se unen a cuatro más en el área del altar-estas sí encendidas-, y que resaltan los colores brillantes dorados del retablo en cuyo centro se encuentra una réplica de la efigie del Señor de los Milagros de Buga. Debido a la altura del techo, el templo presenta una reverberación que produce un eco significativo en el recinto (ver Imagen 1).

12 Este es el núcleo de esta misa en particular y reemplaza lo que en una misa ordinaria serían las oraciones universales. Consiste en un canto intercalado con textos leídos, seguidos de un momento de silencio en el cual se ofrecen al Señor de los milagros las peticiones y necesidades personales.

13 Sobre la demolición del templo de Santa Inés y la reubicación de los retablos, ver Niño y Reina 2010: 259; Malaver 2012, y la página web de la parroquia San Alfonso María de Ligorio (www. xn-seordelosmilagros-gxb.org/nuestra-parroquia/nuestra-historia/). 


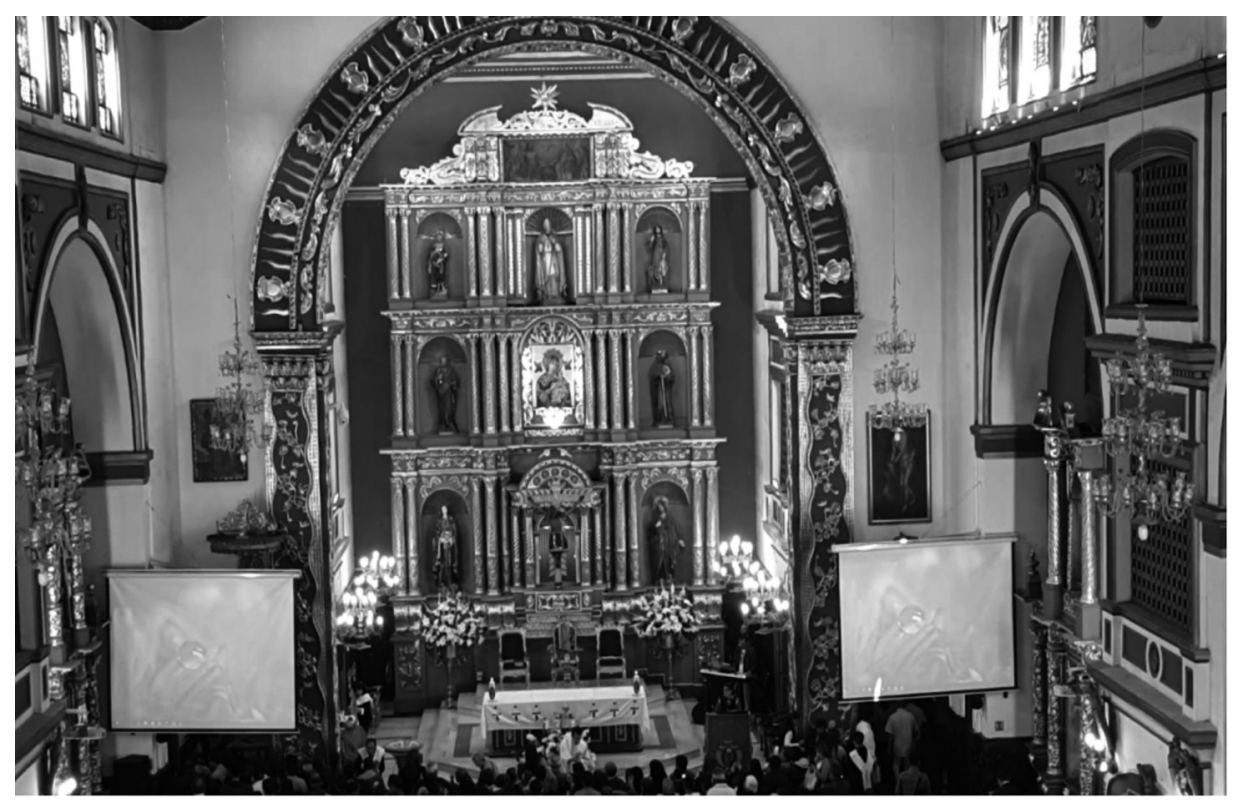

Imagen 1. Retablo de la Iglesia de San Alfonso.

\section{DESCRIPCIÓN Y ANÁLISIS}

Como ocurre habitualmente en esta iglesia, la música estuvo a cargo de un solo intérprete, quien hizo uso de su voz y de un teclado electrónico con sonidos sintetizados, ambos amplificados mediante un sistema de parlantes. Como apoyo a la música se proyectaron las letras de los cantos por medio de dos pantallas dispuestas a ambos lados del altar. De esa manera, la interpretación del cantor principal se vio a menudo acompañada por la participación de los feligreses, y en ocasiones también por la participación del sacerdote. En general, el sistema de amplificación difundió el sonido en un volumen alto para llegar a las casi mil personas presentes, lo que ocasionaba ligeras distorsiones.

En todos los cantos, el cantor utilizó en el teclado sonidos MIDI con distintos timbres (i.e., cuerdas, vientos, percusión, o piano). Este universo sonoro sintetizado sirvió de acompañamiento a una voz masculina con rasgos estilísticos de balada pop-rock (glissandi, vibrato, voz rasgada, etcétera). La mayoría de las canciones utilizadas durante la misa se pueden asociar a los géneros pop y rock. En al menos un par de casos, es evidente la referencia explícita a canciones icónicas de la cultura pop anglosajona y otros cantos aluden estilísticamente a géneros como el country, el R\&B, o más ampliamente al mundo del pop (ver Tabla 2). Algunos mostraron rasgos del pop latinoamericano, como el canto que acompañó el momento de la elevación (ver discusión más detallada abajo). Y hubo particularmente dos cantos que trascendieron este universo estilístico: el canto de salida, estilo salsa, y los Gozos al Señor de los Milagros, un vals cantado a manera de himno. 


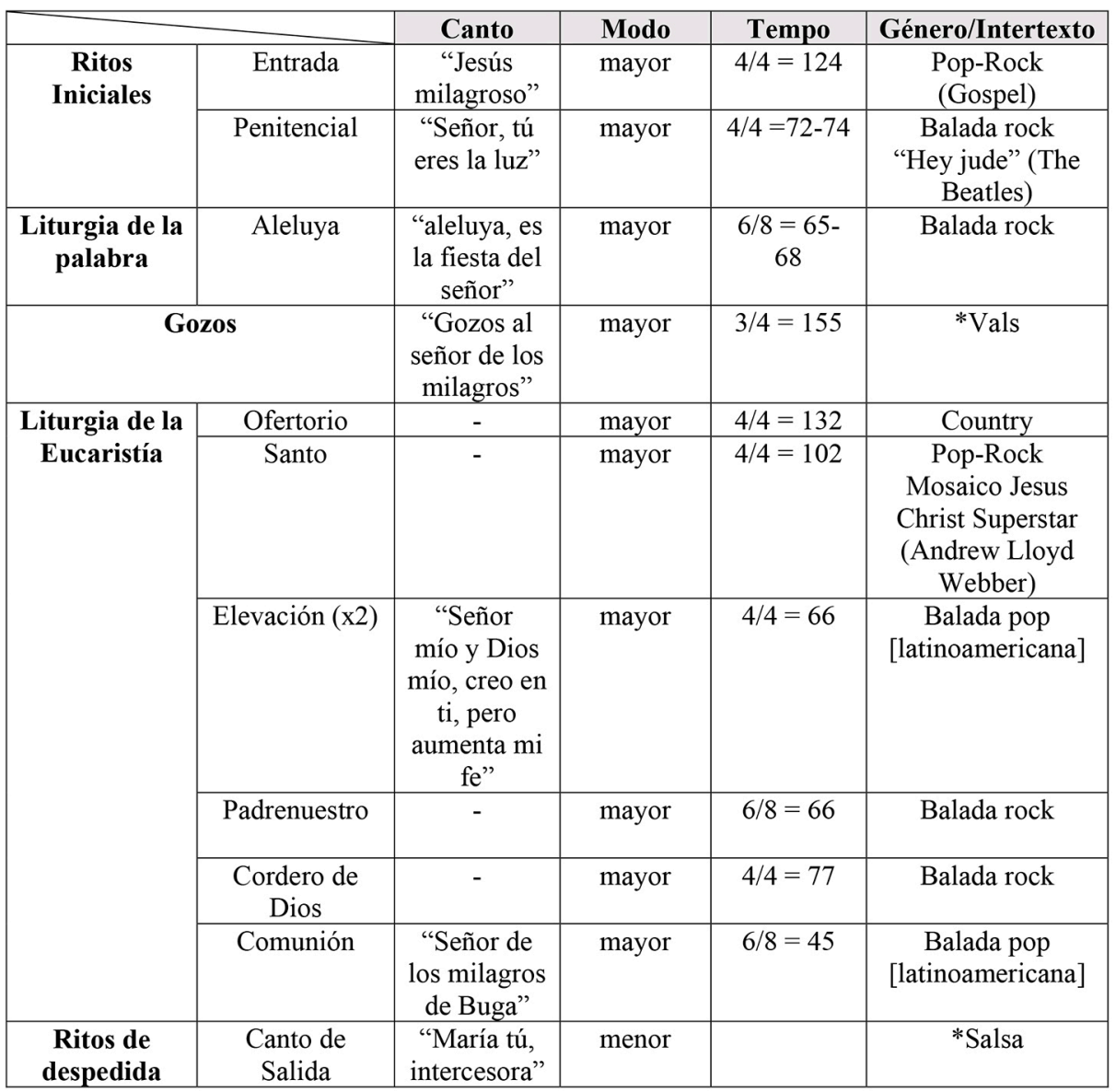

Tabla 2: Caracterización de los cantos de la misa del 14 de junio de 2016 en la parroquia San Alfonso María de Ligorio.

La misa del 14 de junio de 2016 fue particularmente homogénea en términos estilísticos, en comparación con otras misas observadas en la misma iglesia. A continuación describiremos los momentos en que la música muestra una relación especial con otros modos, así como los momentos del ritual en donde se encontró alguna coincidencia con la medición electroencefalográfica de los tres sujetos. La relación entre diferentes modos en la misa de San Alfonso se entiende sobre todo en términos de: 1) nivel semántico del discurso verbal, 2) significado teológico de los diferentes momentos de la misa 3) movimiento corporal de los asistentes y 4) eventos sonoros, incluyendo la música ${ }^{14}$.

14 Aunque la arquitectura y los elementos visuales son relevantes como punto de partida por la mezcla de temporalidades y estéticas que se mencionó antes, no se tuvieron en cuenta en el análisis de cada momento porque permanecen constantes durante todo el ritual. 
Aleluya (m9):

En la misa católica, el Aleluya es un canto festivo de alabanza, que anuncia la lectura del Evangelio. En esta misa consistió en un canto en tonalidad mayor, en métrica compuesta (6/8), con un groove de balada rock y un pulso metronómico de 65 a 68 la negra con punto. En este momento se invitó a la feligresía a ponerse de pie. Esto último, sumado a las características musicales y el contraste con la pasividad de los momentos anteriores (sin música) permite suponer que aquí podrían presentarse aumentos en los valores de valencia y actividad.

\section{Gozos al Señor de los Milagros (m12 - m14)}

El m12 tiene una peculiaridad en cuanto a la interacción multimodal. Por ser los gozos el momento central de esta misa, es de esperar que sean un disparador de respuestas emocionales al coincidir con la intención central de los feligreses que asisten al rito. Sin embargo, los materiales significantes no verbales no apoyaron la relevancia de este momento, pues los gozos sucedieron justo después de una homilía relativamente larga, cuya sección final estuvo acompañada de un incesante llanto de bebé, y cuyo contenido se vio opacado por la acústica reverberante del lugar. Adicionalmente, la cualidad positiva del contenido del discurso verbal del sacerdote (invitación a la alabanza y la plegaria al Señor de los Milagros) contrastó con el tono plano de su discurso. Este contraste se hizo aún más llamativo cuando se le compara con el entusiasmo con que el cantor invitó a la participación de la feligresía en varias ocasiones durante la misa.

A pesar de esta contradicción entre modos, a lo largo de los gozos se evidenció un aumento de la sincronía expresiva entre el tono del discurso, el canto y el contenido verbal. La culminación de esta sección es uno de los momentos de mayor refuerzo multimodal de la misa. En este momento (m14), los sujetos hicieron sus plegarias y peticiones al Señor de los Milagros en silencio, sin música. Esto ocurrió después de la repetición de los gozos intercalada con la parte hablada, que generó un patrón repetitivo y rutinario. El contraste de ese patrón musical con el silencio siguiente contribuyó a un tratamiento sonoro general que redundó en la eficacia emocional de este instante.

\section{Consagración (m17):}

Este es el momento más sublime de la misa por su significado teológico. Durante la elevación ${ }^{15}$ se permite la adición de breves oraciones que, si bien suelen ser hechas en voz baja por cada feligrés, en ocasiones se hacen comunalmente, en forma recitada, cantada o musicalizada ${ }^{16}$. En esta misa el cantor interpretó un pequeño interludio musical con el texto Señor mí y Dios mí, creo en ti, pero aumenta mi fe. Luego de haberse terminado la primera presentación del fragmento, el cantor siguió tocando arpegios en el teclado que acompañaron la consagración del vino. Una vez culminada, esta música de fondo dio paso de nuevo al canto, con el que culminó el momento de la consagración. El entorno sonoro

15 La consagración es el momento en que Jesucristo se hace presente mediante la transubstanciación del pan y del vino en su Cuerpo y su Sangre, que son adorados por los fieles en la elevación (Iglesia Católica 1999).

16 Esta práctica no se encuentra aprobada por la Iglesia católica, ya que se dispone que la elevación debe ser en silencio, y las jaculatorias breves que rezan los fieles deben hacerse en secreto. 
de esta sección fue, en suma, una combinación de la voz solemne del sacerdote y la música de acompañamiento y complemento ya descrita.

Es importante destacar que las características específicas de la música utilizada -tonalidad mayor, métrica binaria en tempo moderado/lento, dinámica piano, baja complejidad melódica, progresión sencilla (I, V, vi x 2, IV x 2, V, IV-V, I), textura instrumental íntima, y voz expresiva- son índice no solo del género balada-pop en general, sino específicamente de la balada romántica. Así, unas características musicales que podrían asociarse típicamente con situaciones de pareja, en este contexto parecen constituir un medio adecuado para reforzar la solemnidad de la presencia mística de la divinidad ${ }^{17}$. Si a esto se añade que durante la consagración muchos feligreses se arrodillaron, algunos con los ojos cerrados, en una actitud de introspección, meditación o adoración silenciosa, se podría afirmar que hay un refuerzo entre diferentes modos de expresión que incluyen el verbal, el del significado teológico, el de las actitudes corporales, y el de los eventos sonoros, incluida la elección musical con sus características sintácticas.

\section{Saludo de paz y canto Cordero de Dios (m20):}

En la misa, el saludo de paz es un espacio que busca suscitar una reconciliación del feligrés con sus semejantes por medio de un saludo de manos. Esta interacción coincide además con la introducción al canto del Cordero de Dios, que correspondió a una música animada, en tonalidad mayor, con timbres brillantes (órgano tipo Hammond), y con un groove de balada rock clásica (ver tabla 2). En este instante se generó un refuerzo evidente entre modos, a causa de la conjunción entre el sentido litúrgico de la paz, el movimiento y la interacción social suscitada, y las características musicales.

Al comparar las dimensiones de valencia y actividad en los tres sujetos a los que se les hizo la medición, no se advierten coincidencias notorias entre las dos dimensiones. Es decir, las veces en que valencia y actividad parecen tener una relación resaltable son particulares en cada sujeto. Existen solo tres momentos en los que las curvas de los tres sujetos expresan un comportamiento similar, aunque solo en relación con una de las dos dimensiones. En cuanto a la actividad, m14 es el único en donde este valor en los tres casos es visiblemente inferior al del momento anterior, lo que coincide con la actividad motora observada. Es decir, hay un descenso evidente en las acciones corporales externas de los tres sujetos, quienes se encuentran de pie, quietos, con los ojos cerrados, y en oración íntima, debido a que m14 corresponde al momento en el que los feligreses hacen sus peticiones personales al Señor de los Milagros (ver Gráficos 1 y 2).

17 Este fenómeno daría cuenta de la idea de Cook (2001), según esta, un cierto tipo de música tiene un campo semántico relativamente amplio pero limitado, que se reduce cada vez que la música entra en contacto con ciertos contextos. En este caso, el campo semántico de la música "romántica" utilizada en la consagración, con una expresión emocional de valencia positiva y bajo nivel de actividad, al ponerse en el contexto del ritual se enfoca en una relación religiosa con la divinidad. 


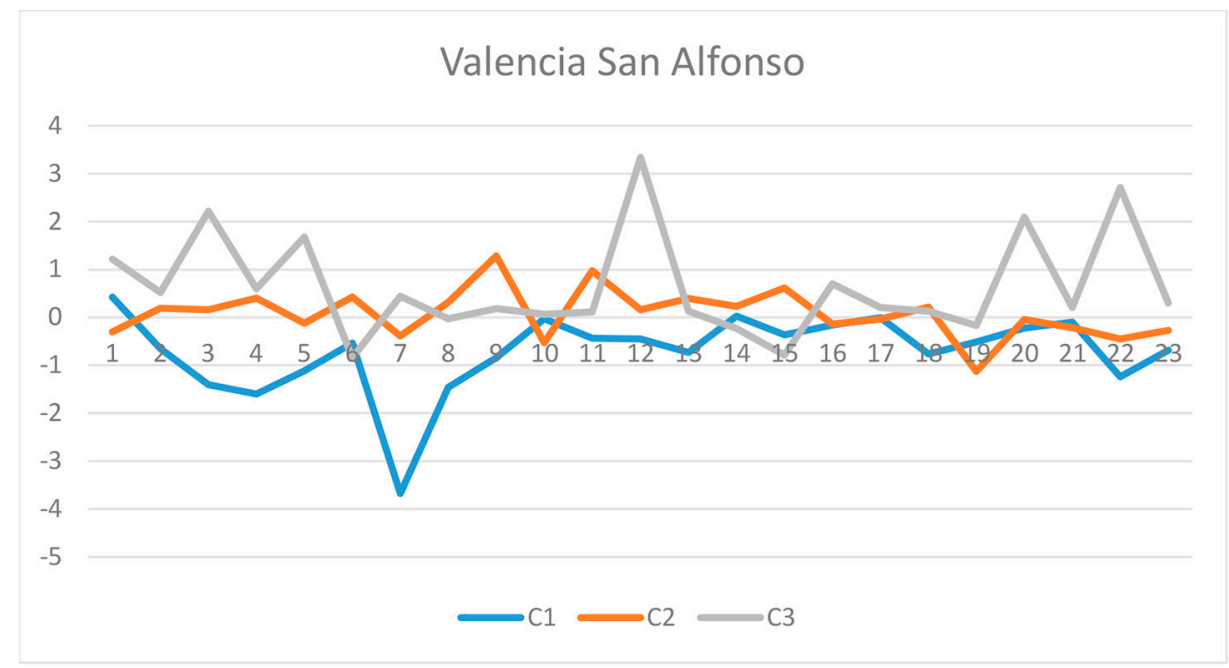

Gráfico 1: Mediciones de la dimensión de Valencia en los tres sujetos de la Iglesia de San Alfonso.

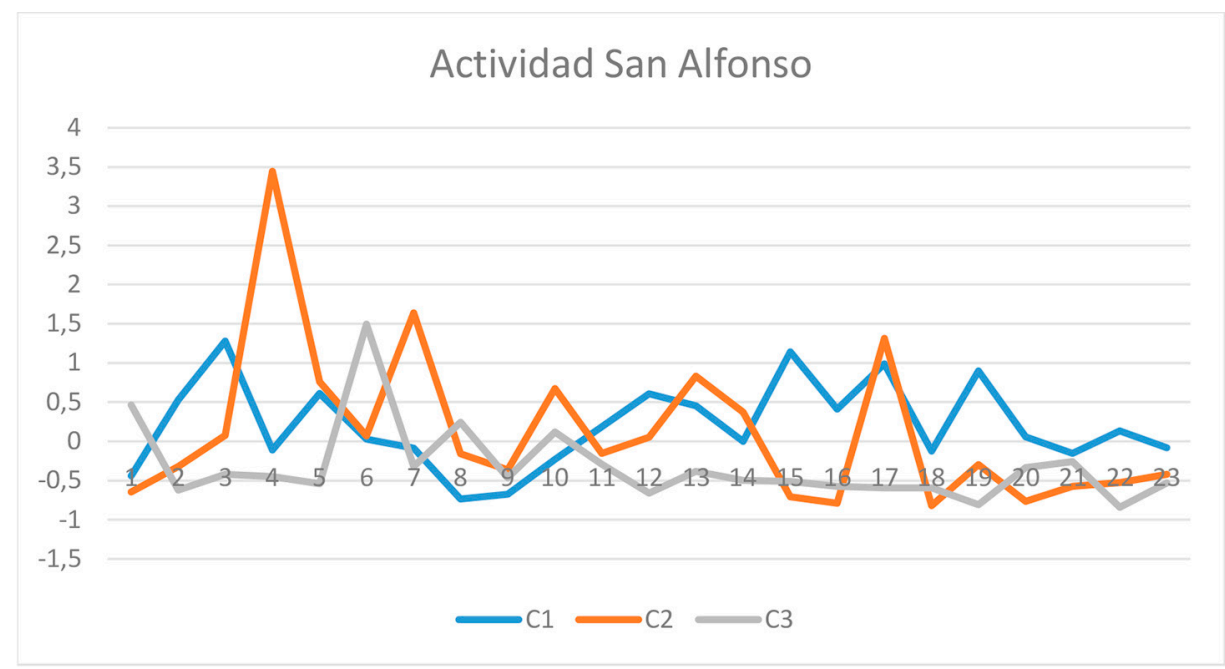

Gráfico 2: Mediciones de la dimensión de Actividad en los tres sujetos de la Iglesia de San Alfonso.

En m9 (canto de Aleluya) que, como se dijo, es un momento de refuerzo multimodal particular, se observa una correspondencia con el aumento simultáneo de valencia en los tres sujetos. Además, m20 corresponde al momento en donde los feligreses se dan el saludo de la paz. En los tres sujetos se advierte una gestualidad y unos movimientos de relajación y de soltura. La interacción social de este momento, unida al inicio del canto Cordero de Dios, puede explicar este aumento en los valores de valencia. Aquí se puede ver que la suma de 
la interacción social y del material musical se corresponde con la respuesta emocional de los tres sujetos.

\section{SÍNTESIS DEL CASO EN LA IGLESIA DE SAN ALFONSO}

Luego del análisis cualitativo de los valores obtenidos de las dimensiones de valencia y actividad, se podría decir que, si bien existen algunas pocas coincidencias entre los tres sujetos, para este rito en particular, los valores corresponden a estados idiosincráticos o coyunturales de cada sujeto. En otras palabras, los datos obtenidos parecen sugerir que el efecto de los materiales del entorno en este ritual no llegan a ser totalizantes, sino que más bien se combinan con lo que Turino (2014) llama el "contexto interno", esto es, el mundo interior de cada individuo. Esto contrasta con la posición del párroco respecto del papel de la música en el rito de la misa católica, según esta, la música funciona como un refuerzo de tipo emocional, ya que sirve para "integrar al pueblo en algo que no es una representación teatral, sino es algo que [se] debe sentir"18. En síntesis, la explicación de muchos de los datos obtenidos parecería obedecer más a aspectos como la personalidad o la coyuntura emocional de los sujetos en ese momento en particular.

Es admisible preguntarse si la naturaleza específica del rito católico puede aminorar el efecto de la narrativa multimodal externa, ya que quizás para los feligreses este pueda ser considerado o experimentado como algo rutinario, debido a la familiaridad que se da por la repetición de la estructura ritual. En cualquier caso, sí es claro que en este ritual no parece haber un refuerzo multimodal sostenido en el tiempo, y eso explicaría, desde nuestro marco conceptual, la dispersión de la respuesta emocional. Por último, y en relación precisamente con esta estructura, resulta interesante anotar que el rol que cumple la música en el rito de la misa católica moderna puede restarle potencia a la influencia que esta puede ejercer en la feligresía. En las misas modernas los fragmentos musicales tienden a ser cortos, están presentes de manera intermitente y en momentos relativamente distanciados en el tiempo, lo que no permite una conexión lo suficientemente continua para lograr un grado significativo de involucramiento (engagement). La desconexión que producen largas zonas de discurso verbal, muchas veces sin participación activa, y altamente convencionalizadas le resta potencia al posible efecto de las experiencias musicales. Así pues, desde la observación de los datos obtenidos, se podría decir que, en el caso del rito católico, la narrativa particular del rito hace que los refuerzos entre modos sean escasos y dispersos y estén subordinados a una estructura predeterminada, por lo que no inciden en una respuesta emocional coordinada de la colectividad.

\section{SALAT YUMMA (ORACIÓN PRINCIPAL DEL VIERNES) EN LA MEZQUITA ESTAMBUL}

Siendo una confesión minoritaria en Colombia, y a pesar de los prejuicios que ha debido confrontar en el panorama contemporáneo, el Islam sobresale como la religión de más rápida difusión a nivel mundial (Castellanos 2010: 11). Bogotá ha sido testigo de ese crecimiento, contando desde 1979 con la Asociación Benéfica Islámica, y ahora con mezquitas como la recientemente construida Abu Bark as-Siddiq, la Mezquita al-Reza de corte chiita, y la Mezquita Estambul de identidad sunita (Centro Islámico de Colombia). Fue en esta última donde se llevó a cabo esta fase de la investigación, tomando como base la oración

18 Entrevista realizada el 24 de febrero de 2016. 
del viernes a mediodía (salat yumma), considerada por los musulmanes como la más importante de la semana. Conviene señalar que, a partir de la muerte de Mahoma, se desprendieron dos corrientes conocidas como sunismo y chiismo, siendo la primera la que identifica a la mayoría de los musulmanes en el mundo, y que reconoce al califato como modelo político en su tradición (sunna) y a Mahoma como el primer sunita. La línea chiita, por su parte, se fundamenta en los doce imanes o seguidores de Alí, yerno de Mahoma, siendo una corriente minoritaria en el islam, pero de amplia representación en países como Irán (Duro 2004: 103).

La Mezquita Estambul de Bogotá exhibe ciertas particularidades importantes, pues no se trata de una construcción convencional de arquitectura islámica, sino de una casa del estilo inglés propio del barrio Teusaquillo, cuyo salón principal fue adaptado para los hombres en la planta baja, mientras las mujeres ocupan un espacio separado en el segundo nivel (desde allí observan lo que sucede abajo, por un televisor). El registro para este análisis se realizó en la sección para hombres, donde varios retazos de alfombras de color rojo (con ilustraciones y arabescos de tonos ocres) cubren el salón en una disposición diagonal respecto de las paredes, facilitando así la ubicación de los fieles en dirección hacia La Meca. La iluminación natural de las ventanas estimula la visión de los detalles al interior, aunque más allá de las alfombras son pocos los elementos decorativos del recinto. Sobre las paredes, divididas entre una gran franja superior de color verde y otra inferior de tinte marrón oscuro, se pueden apreciar algunos cuadros con caligrafía árabe, y justo al lado de los sujetos seleccionados para el análisis, una fotografía enmarcada con la imagen del Masjid al-Haram: primer lugar santo del islam, donde los musulmanes hacen circunvalaciones en torno a la Kaaba ${ }^{19}$ durante su peregrinación.

El llamado a la oración (adhān) se escucha minutos antes del yumma para convocar a los musulmanes a la mezquita. A diferencia de otros templos islámicos que cuentan con un minarete y parlantes externos para la realización del llamado, el de la mezquita Estambul se convoca desde la puerta o el interior de la casa, en ocasiones incluso sin amplificación. Enseguida viene la ablución o $w u d u$, la que consiste en el lavado con agua de manos, boca, nariz, rostro, cabeza, antebrazos y pies, con el fin de purificar el cuerpo para iniciar la oración (Castellanos 2010). Una vez comenzada la sesión, se puede reconocer una estructura de dos partes que coincide con lo observado en la Mezquita Estambul de Bogotá, así:

1. Khutba: corresponde al sermón del imam que dirige la oración. Puede incluir una sección en español, pero debe incorporar también un segmento en lengua árabe.

2. Los musulmanes se ubican en filas, dirigiéndose frontalmente hacia La Meca para las súplicas. Se observa una sincronía en la disposición corporal, pues llevan recurrentemente la frente al suelo como símbolo de sumisión a Dios, siguiendo los movimientos (ver Tabla 3).

19 Cubo sagrado que conecta lo terrenal con lo divino, ubicado en la gran mezquita de La Meca (Arabia Saudita). 


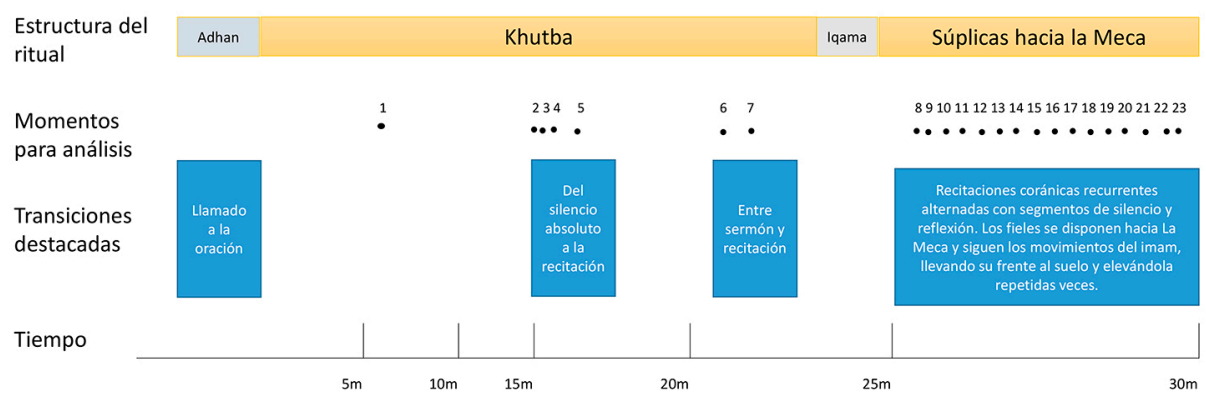

Tabla 3: Estructura del rito de la Mezquita Estambul.

Se trata, en otras palabras, de una estructura bipartita en la que los materiales sonoros alternan entre declamaciones planas del sermón (tanto en español como en árabe) y recitaciones coránicas en lengua árabe, las que exhiben un notable grado de elaboración melódica y melismática. Si bien se presentan algunas recitaciones de este tipo durante el khutba, las más recurrentes y complejas se entonan durante la segunda parte de la oración. Un detalle que llama la atención respecto de la proyección acústica del sonido, es que una vez iniciada la oración en la mezquita Estambul, sí se utilizó un sistema de amplificación con elevados niveles de reverberación y una intensidad de volumen que, para el espacio reducido del recinto, sobrepasaba recurrentemente los límites de saturación. Según el testimonio de Carlos Sánchez, director de esta mezquita, el imam encargado de la oración es quien toma decisiones acerca de este tipo de detalles en la amplificación, tal vez con la intención de emular la resonancia y el eco de otras mezquitas con propiedades acústicas distintas. Conviene destacar este énfasis en el sonido, sobre todo si se tiene en cuenta que, entre las directrices de esta mezquita en particular, se sugiere evitar todo tipo de música, tanto en los espacios de oración como en contextos cotidianos ${ }^{20}$.

\section{DESCRIPCIÓN Y ANÁLISIS}

Nuestra posición como observadores externos al islam hace difícil desvincular el concepto de "música" de los recursos sonoros presentes en el $a d h \bar{a} n$ o en las recitaciones coránicas del ritual. Respetando la acepción de los musulmanes frente a la cualidad sacra de dichos recursos, utilizaremos el término "recitación" 21 en reemplazo de "música", teniendo en consideración que ambos conceptos cumplen funciones similares de acuerdo con la experiencia observada.

A partir de los veinticuatro momentos seleccionados, identificamos aquellos segmentos que nos permitieron reconocer algún tipo de relación entre distintos modos de lenguaje (texto, recitación, movimiento corporal, etcétera) y las respuestas emocionales registradas durante la medición. Los momentos que analizamos a continuación dan cuenta de algunas de esas relaciones en distintos puntos del ritual.

20 Entrevista a Carlos Sánchez realizada el 20 de abril de 2016.

21 Para el análisis, nos concentramos en las recitaciones coránicas de la oración colectiva, cuyos textos provienen de las suras o capítulos del Corán. 
Una de las transiciones más determinantes del yumma se presenta al finalizar el khutba. En ese instante se escucha un nuevo llamado a la oración (iqama) que, a diferencia del adhān inicial, invita a la segunda parte del rito por medio de una recitación menos extensa, la que se ejecuta mientras los fieles se disponen, de pie, en dirección a La Meca. Durante las entrevistas a los tres musulmanes que autorizaron su registro electroencefalográfico, se hizo mención de una de las voces más reconocidas internacionalmente por sus grabaciones de recitaciones coránicas acerca de las suras: Mishary Rashid Alafasy. Esto indica que, si bien se evita la música, sí existen íconos de interpretación vocal que se han convertido en referentes globales, y que se conocen en Colombia gracias a la difusión de grabaciones en plataformas virtuales.

Habiendo escuchado el iqama, y tras dos minutos de oración preliminar, todos los fieles se ponen de rodillas al escuchar una recitación de las palabras Allahu akbar (Dios es grande), apoyando sus frentes sobre la alfombra en señal de sumisión. Aunque no es el objeto de este artículo entrar en los detalles numéricos del registro electroencefalográfico, llama la atención que los tres sujetos observados presentaran declives en la medición de su actividad o arousal, justamente en este instante que presenta mayor movilidad física con relación al khutba. Esto sugiere que puede existir alguna relación entre el texto, el cambio de disposición corporal y la respuesta emocional de los individuos. (ver Imagen 2).

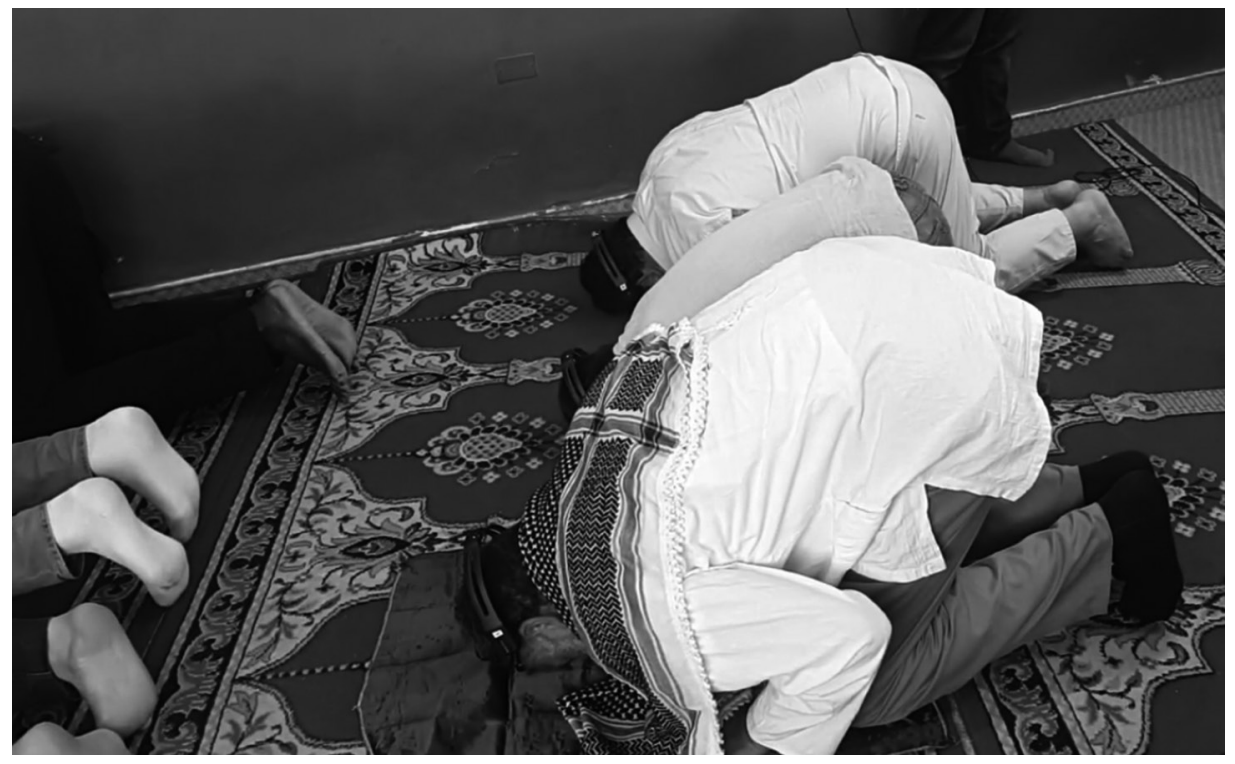

Imagen 2: Primera disposición de rodillas después del iqama, bajo la recitación Allahu akbar.

Los involucrados se mantienen en esa posición de recogimiento, aun cuando la recitación ha finalizado y el recinto se mantiene por nueve segundos en silencio. La actividad (arousal) sigue descendiendo en dos de los fieles, pero llama la atención que asciende significativamente en el tercero, lo que descarta la posibilidad de encontrar patrones homogéneos de respuesta emocional. De igual manera, corroboramos durante la medición que uno de los tres sujetos frecuentemente se distanciaba de los demás tanto 
en valencia como en actividad, lo que resalta, por supuesto, la individualidad de cada experiencia religiosa, aun cuando se comparten los refuerzos sensoriales de un mismo culto y ambientación.

Aun así, fue posible identificar instancias en donde los tres individuos presentaron comportamientos similares. Uno de los momentos más interesantes al respecto ocurrió poco más de un minuto después, mientras el imam recitaba las palabras Idhā Zulzilati Al-'Arđu Zilzālahā (Cuando sea sacudida la tierra por su terremoto). Teniendo los tres las manos recogidas sobre sus brazos cruzados, este segmento de cuatro segundos exhibe uno de los únicos momentos en los que todos coinciden en respuestas emocionales que apuntan a una misma dirección: todas las valencias descienden, llegando incluso al pico más bajo en uno de los fieles, y todas las actividades ascienden, alcanzando uno de los picos más altos en dos de ellos.

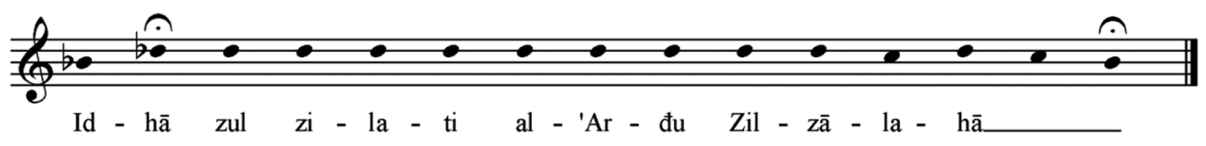

Transcripción 1: m11 de la medición ${ }^{22}$

A diferencia de otras recitaciones, caracterizadas por un comportamiento melismático, esta frase en particular es predominantemente silábica, lo que sugiere también una mayor facilidad para entender el significado de las palabras (ver Transcripción 1). Teniendo en cuenta que los tres sujetos observados tienen conocimientos de lengua árabe, la comprensión semántica se presenta aquí como un elemento que justifica sus correspondencias en respuestas emocionales. Sumando este factor a la disposición corporal y a la expresividad de la recitación, se puede decir que este es un momento de refuerzo multimodal.

22 Teniendo en cuenta que las recitaciones no se sujetan a una métrica regular, optamos por utilizar notas sin plica, y omitir barras de compás. Los calderones representan pequeñas pausas en el ritmo, las que generalmente guardan relación con algunas sílabas acentuadas en la prosodia del texto en árabe. Las notas sin calderón representan cierta fluidez, sin caer en ninguna medición estricta de valores rítmicos. Las alteraciones (bemoles) se presentan solo la primera vez, asumiendo su continuidad en el resto de la transcripción. Conviene mencionar, además, que estas transcripciones cumplen una función ilustrativa para identificar el contorno de las alturas, y así relacionar su distribución respecto de las sílabas del texto, pero no dan cuenta de las inflexiones microtonales presentes en el manejo modal de las recitaciones coránicas. 


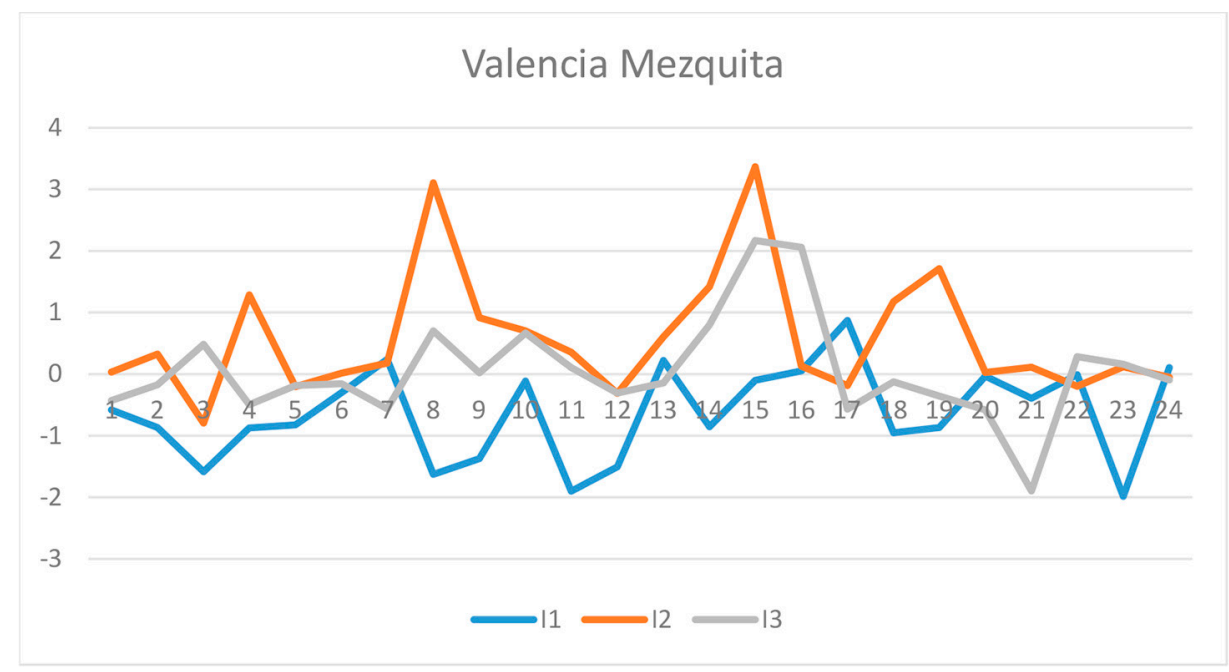

Gráfico 3: Medición de la dimensión de Valencia en los tres sujetos de la Mezquita Estambul.

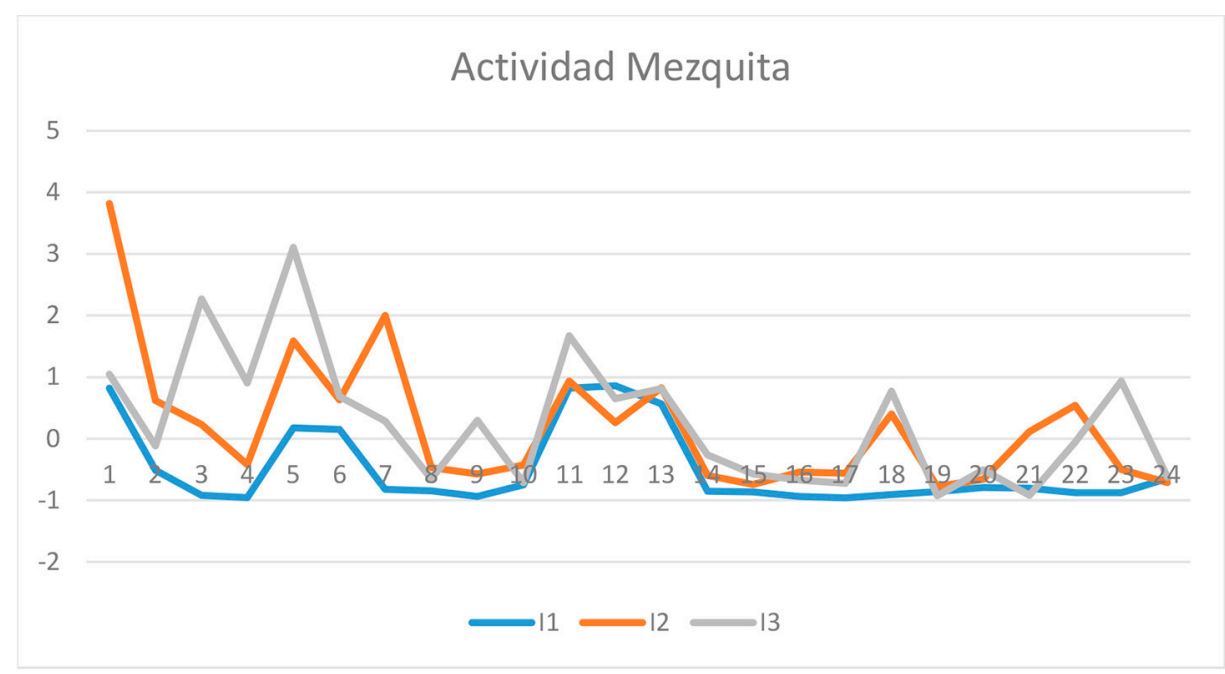

Gráfico 4: Medición de la dimensión de Actividad en los tres sujetos de la Mezquita Estambul. 
El valor semántico de los textos parece, además, guardar una relación coherente con el ascenso de valencias que se presenta consistentemente en dos de los sujetos, a partir de este instante (ver Gráficos 3 y 4). Para ilustrarlo, tengamos en cuenta la traducción completa de los distintos versos de esta recitación:

"Cuando sea sacudida la tierra por su terremoto, expulse la tierra su carga y el hombre se pregunte: '¿qué es lo que pasa?', ese día contará ella sus noticias, según lo que tu Señor le inspire. Ese día los hombres surgirán en grupos, para que se les muestren sus obras. Quien haya hecho el peso de un átomo de bien, lo verá. Y quien haya hecho el peso de un átomo de mal, lo verá"23.

Finalizando esa recitación, se aclama nuevamente a Dios mediante la reiteración de la alabanza Allahu akbar, y es interesante que la valencia emocional de los tres sujetos presente principalmente movimientos ascendentes. Esto podría corresponder a una intensificación de las emociones que resulta de una acumulación sintáctica, siendo entonces el texto un factor determinante que, aunque se refuerza con otros elementos del entorno (visuales y sonoros), podría ser el más influyente en la reacción de los sujetos.

Aunque estos segmentos corresponden a la segunda parte del ritual, esto no significa que los acuerdos o correspondencias entre los sujetos estuvieran ausentes en el khutba. Tampoco quiere decir que el peso determinante del texto deba restar importancia al poder envolvente de la recitación como recurso sonoro. Pudimos observar, por ejemplo, que el rito en general fue logrando gradualmente la atención y concentración de los asistentes. Teniendo en cuenta que el recinto no exhibe las características de las grandes mezquitas de arquitectura islámica tradicional, que la parte trasera del salón presentaba algunos elementos ajenos a la oración (cobijas, maletines y otros artículos arrinconados al fondo), y que no todos los fieles ingresaban puntualmente, podríamos afirmar que había distintos factores que inevitablemente causaban distracción. Aun así, momentos tempranos en el khutba como la recitación melismática sobre las palabras Wal lahu yad uu ila daaris salaam (Dios invita a la casa de paz) provocaron picos ascendentes en la actividad de los sujetos, lo que sugiere también un impulso para recuperar la atención y concentración de los asistentes (ver Transcripción 2):

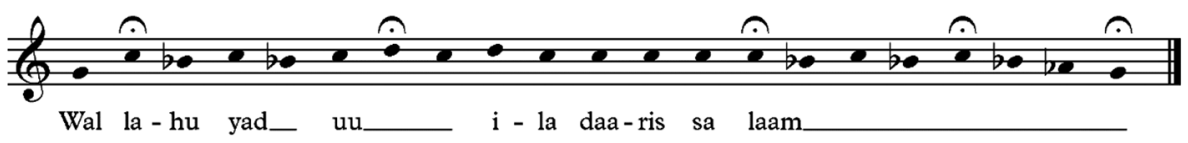

Transcripción 2: m5 de la medición.

Otros momentos de alta relevancia semántica, como el saludo de paz hacia el final de la oración, develaron reacciones heterogéneas en las mediciones de cada individuo, pero aun así es interesante observar la respuesta corporal que se genera a partir de códigos ya aprendidos y compartidos por los musulmanes. Todos vienen de orar en silencio, hasta el anuncio de la paz que se reconoce tan pronto el imam entona su recitación con las palabras Assalam alaikum wa rahmatul lah (La paz de Dios sea con ustedes). La reacción inmediata de todos consiste en girar la cabeza a la derecha e izquierda, con el fin de dar el saludo de

23 Esta y todas las traducciones del original en árabe fueron realizadas por Jamid Sánchez, miembro activo de la mezquita Estambul de Bogotá. 
paz al ángel del bien y del mal, respectivamente. Mientras eso sucede, cada persona susurra las mismas palabras de la recitación (ver Transcripción 3):

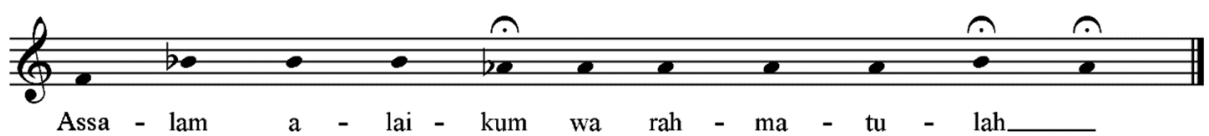

Transcripción 3: m23 de la medición.

\section{SÍNTESIS DEL CASO EN LA MEZQUITA ESTAMBUL}

A diferencia de rituales como los de la Iglesia Pentecostal y San Alfonso, las respuestas emocionales de los musulmanes suníes, en la mezquita Estambul, son menos visibles. Presentan, además, comportamientos de obediencia que siguen parámetros bastante específicos respecto de la estructura de la oración, particularmente durante la segunda parte del rito (posterior al khutba). La coordinación de los fieles, su posición de humildad y movimientos corporales en dirección a La Meca, las salutaciones y mensajes de paz a sus ángeles del bien y del mal, son algunos de los referentes más activos en la disposición física de los musulmanes. Por lo demás, el comportamiento durante el yumma se concentró, más bien, en estados de relajación y concentración sin mayor actividad motriz, lo que generó algunos desafíos en la observación, al no delatar visualmente grandes contrastes de respuesta emocional.

Aun así, las mediciones electroencefalográficas permitieron identificar reacciones que sugieren posibles vínculos entre la respuesta emocional y un refuerzo que reúne distintos modos de lenguaje. El texto, por ejemplo, sobresale como uno de los factores más determinantes en este rito, pues fue posible observar patrones de intensificación en valencias emocionales, tal vez como consecuencia de la acumulación de materiales semánticos. Esto no significa que la relación de causalidad entre el refuerzo multimodal y las emociones resultantes sea directamente demostrable en este caso, pero llama la atención que se haya presentado este tipo de correspondencias en segmentos con un peso importante de contenido verbal.

\section{CULTO DOMINICAL EN LA IGLESIA PENTECOSTAL UNIDA DE COLOMBIA (IPUC)}

La Iglesia Pentecostal Unida de Colombia es la denominación no católica con mayor número de fieles en el país. Con un origen protestante, la iglesia pentecostal surgió a inicios del siglo XX en Estados Unidos como un movimiento religioso que apelaba a una experiencia personal con Jesucristo dada por el bautismo en el Espíritu Santo. Acompañada de experiencias como la glosolalia y el avivamiento (conversiones masivas de no creyentes), se instaló en Latinoamérica producto de los procesos de modernización y urbanización de mediados del siglo XX. De manera particular se presenta como un movimiento que promueve el "uso de la música para alcanzar éxtasis religiosos” (Beltrán 2013). La Iglesia Pentecostal Unida de Colombia se fundó en 1937, y cuenta hoy con varias sedes en Bogotá24.

24 Ver la página oficial de la IPUC para más información https://ipuc.org.co/ 
Para este proyecto se trabajó en la sede de Teusaquillo (IPUC Central). Allí existen varios momentos de culto a lo largo de la semana, pero el más importante se realiza los domingos, junto con otro espacio dedicado a la evangelización que se denomina Escuela Dominical. El culto se realiza en un espacio cuyo interior se asemeja a una sala de cine de los años sesenta. Las paredes de la parte donde se encuentran las sillas son de ladrillos color rojo oscuro, con poca iluminación. Este espacio contrasta fuertemente con el escenario (el altar) que es de paredes blancas y alfombra azul, y está iluminado con luces azules y blancas. Allí se encuentran varios asientos para los pastores y otros celebrantes y está el grupo musical, compuesto por teclado, bajo, batería, congas, guitarra, saxofón alto, trombón, trompeta, y un grupo de seis a ocho coristas, más un director. Este contraste entre el espacio de las sillas y el espacio del altar coincide con oposiciones construidas culturalmente entre oscuridad/ humanidad/pecado y luz/divinidad/gracia. En este entorno, las canciones de alabanza y adoración comunican mediante sus letras el llamado a entregarse a Dios, lo que es reforzado por la disposición contrastante del espacio. La densidad del formato instrumental contribuye a este refuerzo al crear una sonoridad mucho más envolvente e inmersiva que en otros rituales religiosos. En resumen, el contenido privilegiado por el marco general del ritual es el de la entrega incondicional a un poder superior.

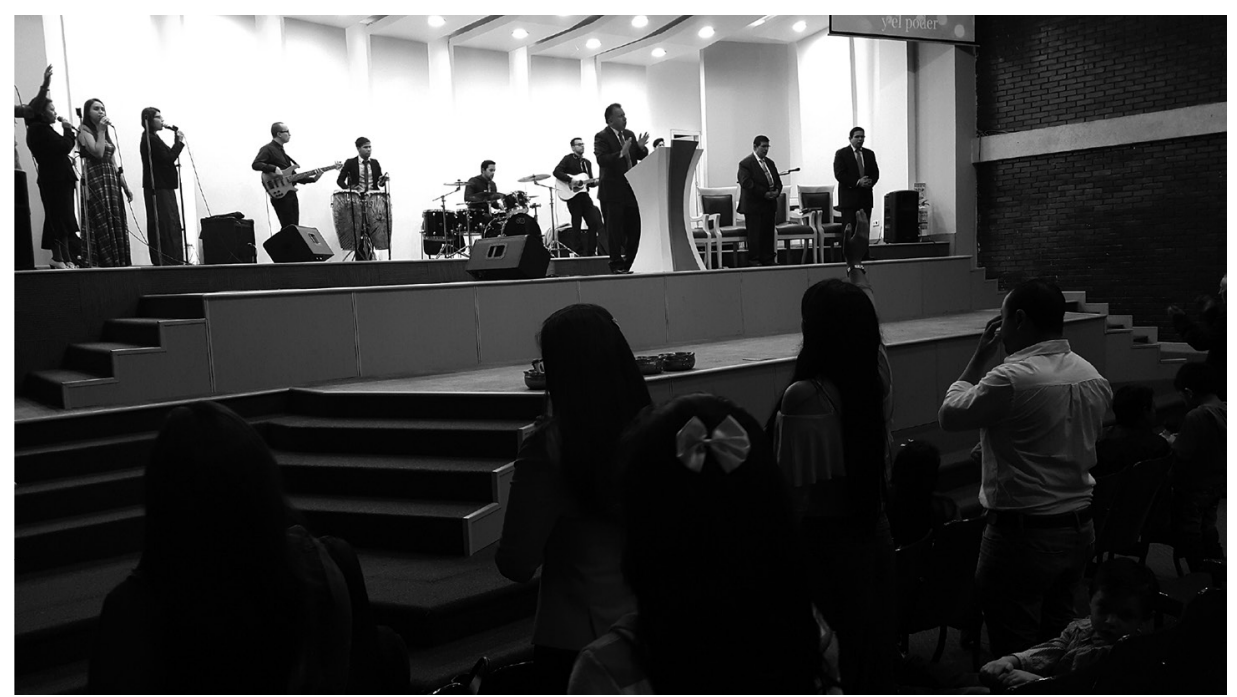

Imagen 3: Fotografía del culto de la Iglesia Pentecostal Unida de Colombia (IPUC Central), realizado el 10 de julio de 2016.

La disposición del grupo musical en tarima es similar a la de un concierto de música popular, con el o la cantante en un primer plano, y los coristas y el resto de la banda atrás (ver Imagen 3). Las canciones siguen modelos musicales del pop en términos de forma, armonía, construcción melódica y ornamentación; la mayoría de estas han sido grabadas por artistas cristianos reconocidos nacional o internacionalmente, lo que implica que tienen un proceso de producción musical detrás y, probablemente, objetivos comerciales para el público cristiano hispanohablante. Es común que estas canciones suenen en emisoras cristianas y estén disponibles en plataformas digitales como YouTube o Spotify. Los miembros de la comunidad, por tanto, tienen la posibilidad de escuchar la misma música que escuchan el domingo en sus casas, creando vínculos particulares con ciertos repertorios (algo que se corroboró en las entrevistas realizadas con los sujetos de la medición). 


\section{DESCRIPCIÓN Y ANÁLISIS}

La actividad musical de la sesión observada y medida se dividió en tres grandes secciones o bloques musicales, articulados por oraciones colectivas guiadas desde el escenario. De acuerdo con el contenido temático verbal de las canciones, y al material musical característico en cada una de las secciones decidimos llamarlas, respectivamente: alabanza inicial, alabanza (poder), y alabanza (recogimiento). Esta estructura varía mucho entre una sesión y otra, pues no hay unos momentos predeterminados para la música. En términos generales, se comienza con canciones de alabanza, luego hay una lectura bíblica, y luego oraciones acerca de diferentes temas. De acuerdo con el líder musical de la iglesia, intercaladas con estas oraciones pueden ir canciones vinculadas al contenido de la oración. Estas pueden prolongarse o recortarse, y buena parte de las decisiones se toman en el mismo momento de la ejecución. Aquí la música es vista como una forma de expresión que complementa el sentido de las oraciones ${ }^{25}$.

Antes de ahondar en cada una de las secciones del rito observado, es importante mencionar que los bloques están compuestos por canciones sin pausas entre ellas, lo que causa que la cadencia final de cada bloque sea un momento importante en la estructura emocional del culto(ver Tabla 4). El primer bloque musical corresponde con los momentos entre m1 y m5 y está formado por dos canciones: A Él alto y sublime y Canta al Señor (Shout to the Lord), ambas en la tonalidad de Sol mayor y en un tempo lento (57-65 ppm). Durante esta primera sección las letras hablan respecto de la grandeza de Dios y cumplen una función introductoria. En palabras del líder del grupo musical "empezamos con unas alabanzas como para identificarnos con las canciones que nos ayuden a entrar en la presencia de Dios”26. La gente utiliza estas canciones para llegar, saludar a otros miembros de la iglesia y prepararse anímicamente para el culto. En la música, el aumento en la densidad es gradual, la armonía es sencilla, solo tiene un par de dominantes secundarias al sexto grado en la primera canción y hace uso del VIIb en la segunda. Algo interesante en ambas canciones es el uso repetido de cadencias rotas al sexto grado hacia el final, lo cual da como resultado un momento cadencial largo, lento y, aunque conclusivo, no muy fuerte.

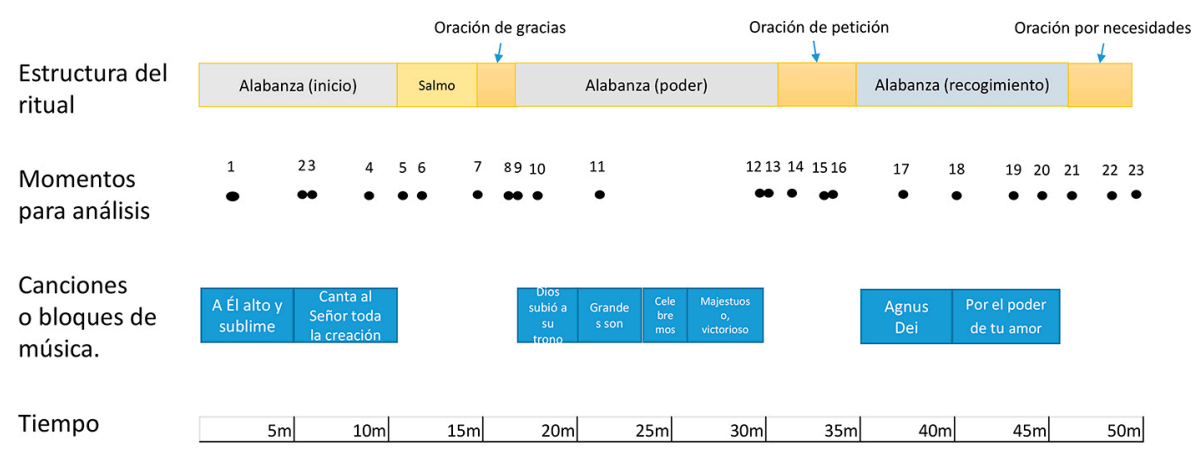

Tabla 4: Estructura del ritual de la IPUC.

25 Entrevista con Sebastián González, líder del grupo musical de la IPUC, el 21 de febrero de 2016.

26 Entrevista con Sebastián González, líder del grupo musical de la IPUC, el 21 de febrero de 2016. 
A continuación se hace la lectura del evangelio y una oración (hablada) que comienza muy calmadamente y va subiendo en intensidad hacia $\mathrm{m} 8$. La voz del pastor lidera este crescendo (la altura máxima de cada frase hablada pasa de un B3 a un F\#4), y es acompañada de un creciente murmullo, ya que cada asistente realiza su propia oración en voz alta. Adicionalmente, durante la oración suenan aplausos aislados cuya frecuencia va aumentando también hacia m8. Durante este minuto y medio la mayoría de los asistentes está de pie, con los ojos cerrados y las manos levantadas hacia el cielo.

Esta oración desemboca en el inicio del segundo bloque musical que está conformado por cuatro canciones: Dios subió a su trono, Grandes son tus maravillas, Celebremos y adoremos, y Majestuoso, victorioso. Todas las canciones fueron interpretadas en si menor, con un pulso de 147 ppm que se mantuvo más o menos estable durante todo el bloque. Las letras buscaban exaltar el poder y la majestad de Dios. El pulso rápido, las letras contundentes, los cortes de batería fuertes y repetidos, y la presencia reiterada de dominantes en finales de frase, junto con los énfasis a la relativa mayor (re mayor), crearon una atmósfera de mucha fuerza. La cadencia final, muy adornada por la batería, ocurrió después de doce minutos seguidos de música, lo que explicaría la intensidad de la respuesta emocional en los sujetos observados (ver discusión más abajo).

A continuación se llevó a cabo una oración por las necesidades de los miembros de la iglesia, realizada por la misma persona que haría la voz principal de las canciones siguientes. La oración también tuvo un crescendo similar a la de $\mathrm{m} 8$, pero alcanza menos intensidad. Esta vez la oración no desemboca en una nueva alabanza, sino se disuelve con una pequeña pausa antes del último bloque de dos canciones lentas: Agnus Dei (Santo) y Por el poder de tu amor, ambas en sol mayor. El pulso es de 67 ppm, pero disminuye entre las canciones hasta llegar a $60 \mathrm{ppm}$. Las letras de este bloque de canciones están relacionadas con el amor y la santidad de Dios, y junto con la armonía predominantemente plagal de la primera canción, ayudan a crear una atmósfera "celestial" y de recogimiento.

En el transcurso de este ritual se identificaron cinco momentos importantes en términos de refuerzo multimodal y respuesta emocional: las cadencias de los tres bloques ( 5 , $\mathrm{m} 12$ y m21) y los picos de las oraciones realizadas entre los diferentes bloques (m8 y $\mathrm{m} 15$ ).

Las características de m5 fueron comparables con las de m20. Ambos señalan la cadencia de los dos bloques de canciones lentas, pero además tienen otros elementos en común: en ambos casos la música está en sol mayor, en ritmo de balada pop lenta y las cadencias están antecedidas por una frase que se repite tres veces con un acompañamiento muy similar ${ }^{27}$. En los dos momentos los asistentes están sentados, con el cuerpo relajado después de haber estado un buen rato de pie, cantando la canción con los ojos cerrados y las manos levantadas. Esa postura corporal, junto con la resolución de la tensión armónica, los aplausos, la voz del pastor que inicia la oración y la prolongación de la cadencia, no solo transmite la idea de cierre, sino de un final satisfactorio y feliz, o de un merecido descanso. Por esta razón es interesante notar que estos dos momentos concluyen un aumento similar de la valencia emocional de los tres sujetos de la medición en relación con los momentos anteriores. La actividad (arousal), en cambio, no muestra algún patrón reconocible en relación con la estructura musical. Esto sugiere que el refuerzo entre diferentes modos afecta en este caso de manera más notoria la dimensión de valencia (positiva) (ver Gráficos 5 y 6 ).

27 En m5 la frase "incomparables promesas me das, Señor" se repite tres veces con la armonía vi - V- IV (iii) y solamente en la última repetición hace dominante y tónica para concluir. En m20 la frase "y me levantaré como las águilas por el poder de tu amor" se repite tres veces con la armonía IV - iii - ii y en la última repetición hace vi - V - IV - V para resolver a tónica. La reiteración de este recurso con materiales musicales similares produce un efecto expresivo equivalente. 


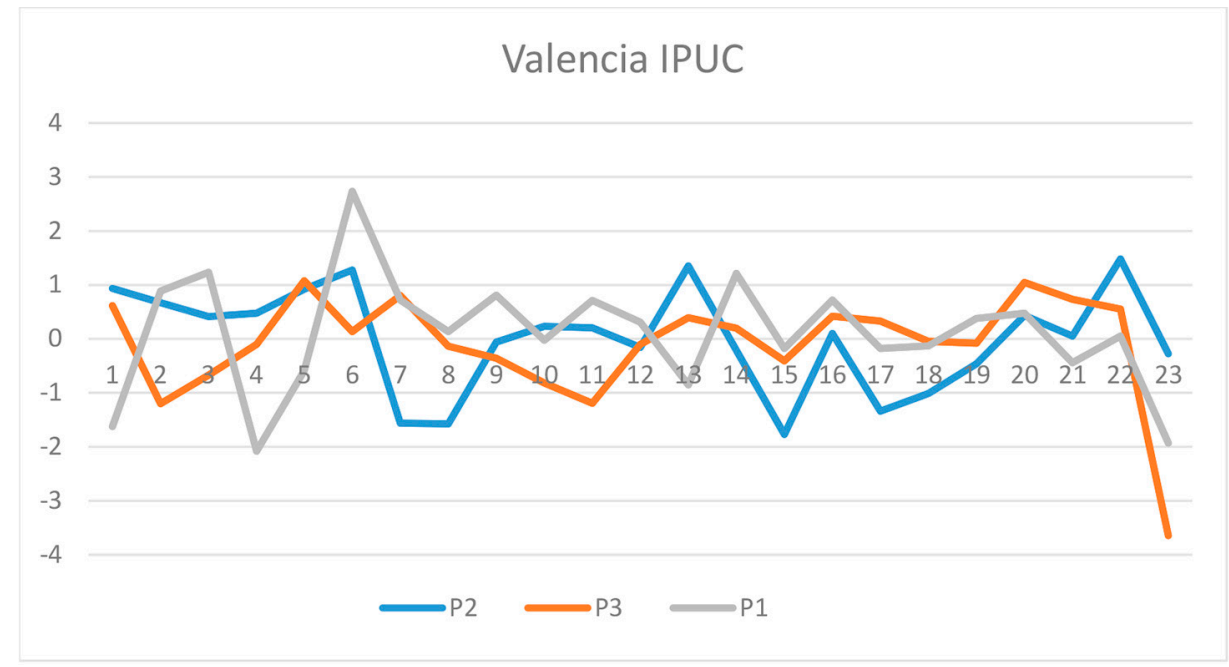

Gráfico 5: Medición de la dimensión de Valencia en los tres sujetos de la IPUC.

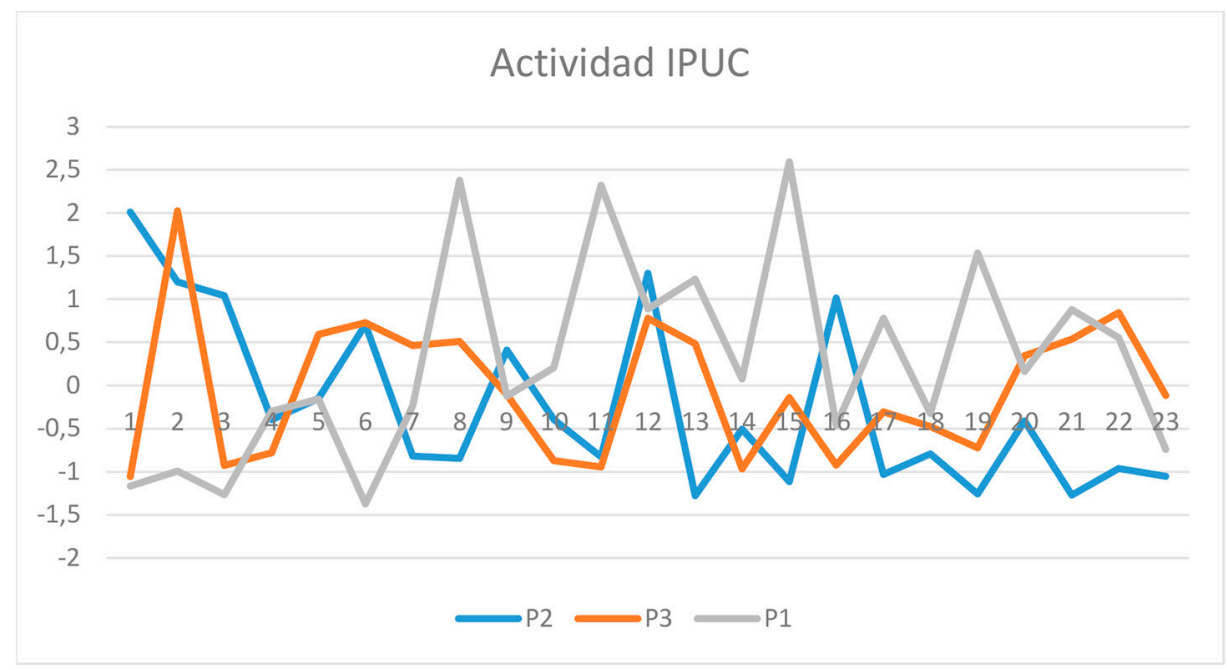

Gráfico 6: Medición de la dimensión de Actividad en los tres sujetos de la IPUC. 
Por otro lado, m12 marca la cadencia del bloque de cuatro canciones rápidas. Al igual que en m5 y m20, aquí se superponen varios elementos que pueden ser disparadores de respuestas emocionales, pues tienen una alta densidad semiótica y varios modos de lenguaje refuerzan la idea de final y de liberación de energía ${ }^{28}$. Sin embargo, al ocurrir después de trece minutos de música con un pulso de 147 y en tonalidad menor, la intensidad de esta cadencia es notoriamente mayor. A esto contribuyen manifestaciones corporales más intensas, como llantos descontrolados con temblores en las manos, brazos estirados hacia el cielo, gritos con voz temblorosa por parte del pastor y los feligreses y un aplauso final que dura un poco más de un minuto. Es de esperar que un momento así se refleje en picos de valencia y actividad en las mediciones. En efecto, este es el único momento en que los tres sujetos coinciden en un nivel alto de actividad, pero no hay un comportamiento similar en la dimensión de valencia. Esto puede deberse a que la intensidad de la experiencia emocional puede estar acompañada por sentimientos contradictorios como culpa, arrepentimiento, felicidad, liberación, entre otros, que dependen de la vivencia particular de cada sujeto. Pero es evidente que la música, en combinación con otros elementos significantes del entorno, funciona aquí como facilitadora de una entrega corporal y emocional casi total al ritual.

Por otro lado, m8 y m 15 señalan los picos de las oraciones entre los bloques musicales. Como se dijo anteriormente, estas oraciones aumentan gradualmente de intensidad y, aunque no hay música, los elementos sonoros son los que más claramente contribuyen a ese aumento (voz del pastor, aplausos, murmullos de oración, gritos). En ambos casos hubo reacciones emocionales diversas. Uno de los sujetos tuvo allí dos de sus picos más altos de actividad (arousal), otro tuvo sus dos picos más bajos de valencia y otro no mostró alguna reacción coherente entre los dos momentos. Es diciente que dos de los sujetos tuvieran reacciones marcadas y similares en los dos picos de oración sin música. Sin embargo, es claro que allí no hubo respuestas tan articuladas como el pico de actividad en m12, o el aumento gradual de la valencia hacia m5 y m20. Es importante mencionar que los tres sujetos experimentan aumentos significativos en la valencia durante los momentos de catarsis o introspección, cuando su comportamiento ya no es guiado por la oración o la música y pueden experimentar una cierta sensación de liberación.

\section{SÍNTESIS DEL CASO EN LA IPUC}

De acuerdo con las entrevistas realizadas, los tres sujetos de la IPUC manifestaron una gran apropiación de los comportamientos esperados para los miembros de su iglesia. Ninguno admitió que bailara como no fuera "danzar en el espíritu", que es una forma de trance que ocurre en raras ocasiones en el contexto más íntimo de la iglesia. Así mismo, procuran escuchar solamente música pentecostal, eventualmente, de otros artistas cristianos, y evitan conscientemente el reguetón y otros géneros que tengan connotaciones sexuales, incluso si tienen letras cristianas. Adicionalmente, en la observación se pudo notar que todas las mujeres llevan falda y todos los asistentes asumen desde el inicio una actitud de incondicionalidad con el ritual, que se manifiesta en la facilidad y la energía con que responden al pastor ("Amén") y adoptan posturas corporales de adoración (arrodillarse, levantar las manos) de forma individual y no necesariamente colectiva, como ocurre en los otros dos rituales estudiados.

28 Los elementos que se superponen en las cadencias -además de la armonía- son: 1) frase final conclusiva de la voz principal, 2) adornos en batería con mucho uso de platillos, 3) aplausos del público, 4) manifestaciones corporales (manos levantadas, ojos cerrados, cabezas hacia arriba), 5) intervención de la voz del pastor con voz muy alta iniciando algún tipo de oración. 
Al mismo tiempo, este es el ritual en el que se observa mayor coincidencia entre los contenidos transmitidos por diferentes modos. Las canciones de alabanza se acompañan de movimientos corporales y gestualidad facial que indican adoración y entrega a un poder superior. A esto se suma una distribución del espacio y un manejo de los colores y las luces que da una relevancia especial a lo que ocurre en el altar, que a su vez funciona como el escenario de un concierto. Durante las canciones rápidas la gente aplaude de pie, mueve el cuerpo y canta las canciones. Los ocasionales cortes rítmicos se usan para reforzar contenidos que hablen de poder y gloria ("Tú eres grande Jehová”) y están acompañados a su vez por movimientos que señalan poder, como levantar los brazos rápidamente. Incluso en las oraciones sin música, la actitud de entrega es reforzada por un componente sonoro que se va intensificando bajo el liderazgo del pastor. Todo este refuerzo multimodal coincide además con una expresión emocional corporal mucho más intensa que la observada en los otros rituales: llanto, ojos cerrados, manos levantadas. El refuerzo también se ve apoyado por la continuidad temática y de carácter que hay durante todo el culto: hay un hilo conductor que no se interrumpe y permite el sostenimiento del refuerzo para la construcción y efectividad del mundo de sentido.

\section{CONCLUSIONES}

En los rituales observados se aprecia una gran diversidad de factores que pueden influenciar la respuesta emocional. Uno de los más importantes es el de las expectativas y vivencias particulares que los sujetos han ido construyendo en su relación con el rito y en su vida espiritual en general. Este factor, evidentemente, es imposible de valorar en una investigación como esta, y trasciende el marco de la experiencia puntual del ritual.

Sin embargo, también fue posible identificar momentos puntuales en los que el entorno de la experiencia, con sus materiales significantes, fue determinante para facilitar una cierta respuesta emocional por parte de los feligreses. La hipótesis con la que iniciamos este proyecto proponía que, a mayor coincidencia o refuerzo entre los contenidos de diferentes modos, se produciría una mayor intensidad en la respuesta y una mayor disposición a obedecer los comportamientos sugeridos por el ritual. No obstante, además de los momentos de refuerzo o contradicción que hemos descrito en cada análisis, encontramos que la estructura de los rituales y sus niveles de predictibilidad, así como la manera en que se construye la sintaxis musical y emocional, son variables relevantes para entender la efectividad de los contenidos significados en la producción de determinadas respuestas por parte de los sujetos.

En primer lugar, existen diferencias en la estructura de los rituales. Mientras la misa católica y el Salat Yumma tienen unas secciones ordenadas de acuerdo con una codificación precisa, el culto de la IPUC puede llegar a presentar variaciones sustantivas en cuanto a las partes que lo conforman. La predictibilidad de la estructura puede estar además potenciada por la familiaridad con los materiales significantes del ritual. En general, se puede decir que el ritual musulmán, al menos para los asistentes a la Mezquita Estambul, presenta una estructura y unos materiales altamente predecibles. La misa en San Alfonso, por otro lado, presenta una estructura predecible, pero con un ligero margen de variación en los materiales musicales. Por último, el culto de la IPUC tiene una estructura variable, pero el contenido sonoro es altamente familiar para los feligreses.

Como se vio en el análisis del ritual católico, encontramos que, a mayor predictibilidad, parece haber un menor peso de los contenidos del entorno en la respuesta emocional. Esto puede deberse a que un guion predeterminado produce menos momentos de sorpresa $o$ rompimiento de expectativas que contribuyan a la activación emocional, y al mismo tiempo 
puede facilitar actitudes contemplativas o de introspección que crean una distancia entre el sujeto y los estímulos del entorno.

Los diferentes grados de predictibilidad de la estructura y los materiales también producen diferentes tipos de sintaxis, tanto en los contenidos musicales como en las emociones propuestas por el ritual. En la misa católica los significados teológicos de las liturgias (de la Palabra y de la Eucaristía) y de sus secciones conllevan una disposición emocional que no siempre es reforzada por el sonido musical (especialmente a partir de la reforma litúrgica que siguió al Concilio Vaticano II, en el que se flexibilizó enormemente el uso de la música). En la IPUC, por el contrario, la música es prácticamente el hilo conductor de la sintaxis emocional, junto con otros elementos sonoros, ya que hay una construcción sostenida y gradual de este tipo de estímulos a lo largo del tiempo del ritual. Estas diferencias sirven para destacar que, si bien en entornos experimentales es posible atribuir respuestas emocionales a eventos musicales discretos (armónicos, melódicos, rítmicos, tímbricos), en entornos complejos como el estudiado se vuelve mucho más relevante la organización de estos elementos en una sintaxis que guarde alguna analogía con la dinámica de la experiencia emocional, como lo sugiere Zbikowski (2010).

Aquí es importante tener en cuenta además que en cada ritual se produce una diferente "jerarquía" de modos: mientras en la IPUC lo sonoro tiene un papel central (música, aplausos, murmullos, llanto, tono del pastor), en la mezquita la medición nos permitió identificar que el discurso verbal es claramente preponderante en la construcción de la sintaxis emocional. Algo similar sucede en el ritual católico, aunque en este caso fue menos evidente la primacía de un modo sobre otros. Lo interesante es que este predominio modal es consistente con la apuesta teológica que hay detrás de la organización del rito, y se vuelve central en la forma concreta que adquiere la experiencia emocional.

Por otro lado, además del ordenamiento temporal, las diferencias en la estructura y la sintaxis también están notoriamente marcadas por el grado de normalización de los movimientos corporales. En la oración de la mezquita cada movimiento tiene un momento preciso y se hace por parte de la feligresía de manera simultánea. Y cuando no hay movimientos los fieles guardan completa quietud. Algo similar ocurre en la misa católica, donde cada parte tiene una postura corporal correspondiente (de pie, de rodillas, sentado, haciendo la señal de la cruz), aunque aquí los movimientos son notoriamente menos precisos que en la mezquita. Por el contrario, en la IPUC no solamente se admite, sino se fomenta una expresión corporal mucho menos uniforme, ya que esta se considera una parte central de la oración que cada fiel hace de manera individual. En los dos primeros casos, la expresión corporal obedece a unos códigos aprendidos con anterioridad (y por tanto responde menos a los estímulos del entorno), mientras que en el último obedece más a la experiencia particular de cada rito, y por ello parece dialogar más con los materiales significantes presentes en dicha experiencia.

Estas diferencias en la estructura (partes), las formas de construcción de la sintaxis emocional y los comportamientos corporales esperados producen distintos niveles de predictibilidad, y estos a su vez parecen tener una relación inversa con la intensidad y la sincronía de las respuestas emocionales de los sujetos de la investigación. Tanto en la mezquita como en la iglesia de San Alfonso, hay unos comportamientos aprendidos durante años en configuraciones similares de cada ritual. Esto puede hacer que los materiales significantes actúen más como un marco estable y familiar para la introspección, y menos como estímulos emocionalmente competentes. Por otro lado, en la IPUC, la variabilidad de la estructura y de los comportamientos esperados hacen que los materiales del entorno -y especialmente la música-actúen como disparadores de respuestas emocionales, lo que conduce a una sintaxis particular para cada sesión del culto. Para ponerlo en términos 
resumidos, la investigación sugiere que, a mayor regulación y predictibilidad, menor protagonismo tienen los materiales significantes del entorno en la experiencia emocional.

En síntesis, de los tres rituales señalados, es evidente que el ritual pentecostal es el que presenta un mayor refuerzo entre modos y una mayor intensidad de la respuesta emocional. Esto se debe en gran medida a que los materiales sonoros están organizados en una sintaxis que facilita transiciones de calma a activación y catarsis. También se debe a que la menor predictibilidad del rito le da más peso a la experiencia de los contenidos del entorno. Pero más interesante aún es verificar que este es el ritual en el que los feligreses se muestran más dispuestos a seguir los comportamientos esperados por la confesión por fuera del ritual. Esto contrasta precisamente con la mayor flexibilidad y aparente menor regulación de los comportamientos dentro del ritual. Pero por eso mismo puede aportar claves para la comprensión del papel que las emociones musicales juegan en el comportamiento de los grupos humanos en el mundo contemporáneo.

Hace pocos años, el premio Nobel de economía Richard Thaler proponía que la economía puede ser mejorada sugiriendo a la gente ciertas decisiones, en lugar de forzar resultados específicos (Thaler 2012: 428). Esto concuerda con el cambio cultural que según varios autores ha caracterizado la transición de las lógicas del capitalismo industrial a nuevas configuraciones como las del capitalismo tardío (Jameson 1991), las sociedades de control (Deleuze 1999) o la modernidad líquida (Bauman 2016). En muchos de estos enfoques se sugiere que una mayor sensación de libertad en la escogencia individual muchas veces constituye una forma enmascarada de subjetivación que de ninguna manera neutraliza el poder, sino que, por el contrario, vuelve mucho más eficiente su ejercicio.

A pesar de tratarse de un estudio de caso imposible de generalizar, esta investigación sugiere que las experiencias caracterizadas por un entorno más flexible e impredecible son más permeables a la acción de los materiales significantes, incluida la música y otros lenguajes no verbales como las imágenes o el movimiento corporal. Por esta razón es importante insistir en la necesidad de seguir estudiando el papel de la música en combinación con otros modos de expresión, con el fin de entender cada vez mejor de qué manera se crean esos mundos posibles, que determinan cada vez más nuestras posibilidades de elegir.

\section{BIBLIOGRAFÍA}

Althusser, Louis

1970 Ideología y aparatos ideológicos del estado. Medellín: Pepe.

Baehr, Elsa; J. Peter Rosenfeld, Rufus Baehr y Carolyn Earnest

1998 "Comparison of two EEG asymmetry indices in depressed patients vs. normal controls”. International Journal of Psychophysiology, XXXI/1, pp. 89-92. DOI: 10.1016/ S0167-8760(98)00041-5.

BARSALOU, LAWRENCE

2009 "Simulation, situated conceptualization and prediction". Philosophical Transactions of the Royal Society, Series B, Biological Sciences, 364, pp. 1281-1289. DOI: 10.1098/rstb.2008.0319.

BAUMAN, ZyGmunt

2016 Modernidad líquida. Madrid: Fondo de Cultura Económica.

BECKER, JUDITH

2004 Deep Listeners: Music, Emotion and Trancing. Indiana: Indiana University Press. 
Beltrán, William Mauricio

2013 Del monopolio católico a la explosión pentecostal. Pluralización religiosa, secularización y cambio social en Colombia. Bogotá: Universidad Nacional de Colombia.

ButLER, JUDITH

2001 Mecanismos psíquicos del poder. Teorías sobre la sujeción (e-book). Valencia: Ediciones Cátedra.

Castellanos, Diego

2010 Islam en Bogotá: Presencia inicial y diversidad. Bogotá: Universidad del Rosario.

Collier, Geoffrey

2007 "Beyond valence and activity in the emotional connotations of music", Psychology of Music XXXV/1, pp. 110-131. DOI: 10.1177/0305735607068890

Cook, Nicholas

2001 "Theorizing Musical Meaning”, Music Theory Spectrum, XXIII/2, pp. 170-195. DOI: 10.1525/ mts.2001.23.2.170

Damasio, Antonio

2007 En busca de Spinoza. Neurobiología de la emoción y los sentimientos. Barcelona: Crítica.

DAVIDSON, R. J.

1995 "Cerebral asymmetry, emotion and affective style", Brain asymmetry, Richard J. Davidson y Kenneth Hugdahl (editores). Cambridge: MIT Press, pp. 361-387.

Deleuze, Gilles

1999 "Post-scriptum sobre las sociedades de control", Conversaciones, José Luis Pardo (traductor). Valencia: Pre-textos, pp. 277-286.

Duro Montealegre, Rosa

2004 "El Islam en el mundo árabe: respuesta a una globalización excluyente", OASIS: Observatorio de análisis de los sistemas internacionales, X/10, pp. 95-115.

Foucault, Michel

1988 "El sujeto y el poder", Revista Mexicana de Sociología, L/3, pp. 3-20.

Gabrielsson, Alf

2010 "Strong Experiences with Music", Handbook of music and emotion. Theory research, applications, Patrick Juslin y John Sloboda (editores). Oxford: Oxford University Press, pp. 547-574.

Gabrielsson, Alf y Erik Lindström

2010 "The Role of Structure in the Musical Expression of Emotions", Handbook of music and emotion. Theory research, applications, Patrick Juslin y John Sloboda (editores). Oxford: Oxford University Press, pp. 367-400.

Gridley, Mark y Robert HofF

2011 "Demand Characteristics and Religiosity in Perception of Emotion in Music", Psychology Journal, VIII/3, pp. 88-92.

Guerra Rojas, Cristian.

2009 "Tiempo, relato y canto en la comunidad pentecostal", Revista Cultura y Religión, III/2, pp. 127-144.

HANSER, WALDIE y RUTH MARK

2013 "Music Influences Ratings of the Affect of Visual Stimuli", Psychological Topics, XXII/2, pp. 305-324. DOI: 10.1037/t11644-000.

Henriques, JefFrey B., y Richard J. Davidson

1990 "Regional brain electrical asymmetries discriminate between previously depressed and healthy control subjects". Journal of Abnormal Psychology, XCIX/1, pp. 22-31. DOI: $10.1037 / / 0021-843 x .99 .1 .22$. 
1991 "Left frontal hypoactivation in depression", Journal of Abnormal Psychology, C, 4, pp. 535-545. DOI: $10.1037 / 0021-843 X .100 .4 .535$

Hernández SALGar, Óscar

2016 Los mitos de la música nacional. Poder y emoción en las músicas populares colombianas 1930-1960. La Habana: Editorial Casa de las Américas.

Hernández, Roberto, Carlos Fernández y Pilar Baptista

2010 Metodología de la investigación científica. México D.F.: Mc Graw Hill.

Iglesia Católica

1999 Catecismo de la Iglesia Católica. Editorial San Pablo.

JAMESON, FREDRIC

1991 El postmodernismo o la lógica cultural del capitalismo avanzado. Barcelona: Paidós.

Juslin Patrick y John Sloboda

2010 Handbook of Music and Emotion. Theory Research, Applications. Oxford: Oxford University Press.

Kapp, B. S, W. F. Supple y P. J. Whalen

1994 "Effects of Electrical Stimulation of the Amygdaloid Central Nucleus on Neocortical Arousal in the Rabbit”, Behavioral Neuroscience, CVIII/1, pp. 81-93. DOI: 10.1037//0735-7044.108.1.81.

Keller, Peter y Emery Schubert

2011 "Cognitive and Affective Judgements of Syncopated Musical Themes", Advances in Cognitive Psychology, VII/2, pp. 142-146. DOI: 10.2478/v10053-008-0094-0.

Krumhansl, Carol

2002 "Music: A Link between Cognition and Emotion". Current Directions in Psychological Science, XI/2, pp. 45-50. DOI: 10.1111/1467-8721.00165.

Lazzarato, Maurizio

2006 Por una politica menor. Acontecimiento y política en las sociedades de control. Madrid: Traficantes de Sueños.

Malaver, CAROL

2012 "55 años después de demoler una iglesia, sus tesoros aun existen”, El Tiempo (11 de mayo). Recuperado en: www.eltiempo.com/archivo/documento/CMS-11777986 [Acceso: 9 de mayo de 2018].

Mauss, Iris B. y Michael D. Robinson

2009 "Measures of emotion: A review", Cognition and emotion, XXIII/2, pp. 209-237. DOI: $10.1080 / 02699930802204677$.

Meier, Brian P., Michael D. Robinson y Gerald L. Clore

2004 "Why Good Guys Wear White: Automatic Inferences about Stimulus Valence Based on Brightness”, Psychological Science, XV/2, pp. 82-87. DOI: 10.1111/j.0963-7214.2004.01502002.x.

Miller, Mandi y Kenneth Strongman

2002 "The Emotional Effects of Music on Religious Experience: A Study of the PentecostalCharismatic Style of Music and Worship", Psychology of Music, XXX/1, pp. 8-27. DOI: $10.1177 / 0305735602301004$.

Niño, Carlos y SANDra Reina

2010 La carrera de la modernidad. Construcción de la carrera décima. Bogotá (1945-1960). Bogotá: Instituto Distrital de Patrimonio Cultural.

North, Adrian \& David Hargreaves

2008 The social and applied psychology of music. Oxford: Oxford University Press.

Penman, Joshua y Judith Becker

2009 "Religious Ecstatics, 'Deep Listeners', and Musical Emotion”, Empirical Musicology Review, IV/2, pp.49-70. DOI: 10.18061/1811/37474. 


\section{Rosenfeld, J. Peter y Elsa Baehr}

2003 "EEG biofeedback ("Neurofeedback") and affective disorders", Consciousness, Emotional SelfRegulation and the Brain, Mario Beauregard (editor). Filadelfia: John Benjamins Publishing Company.

Rouget, Gilbert

1985 Music and Trance. A Theory of the relations between Music and Possession. Chicago: University of Chicago Press.

Russell, James A.

1980 "A Circumplex Model of Affect", Journal of Personality and Social Psychology, 39/6, pp. 11611178. DOI: $10.1037 /$ h0077714.

Sloboda, John y PATrick Juslin

2010 Handbook of music and emotion. Theory research, applications. Oxford: Oxford University Press.

Sollberge, Bernhard, Rolf Rebe y Doris Eckstein

2003 "Musical chords as affective priming context in a word-evaluation task", Music Perception, XX/3, pp. 263-282. DOI: 10.1525/mp.2003.20.3.263.

THALER, RichARD ET AL.

2012 "Choice Architecture", The Behavioral Foundations of Public Policy, Eldar Shafir (editor). Princeton: Princeton University Press, pp. 428-439.

Turino, Thomas

2014 "Peircean Thought As Core Theory For A Phenomenological Ethnomusicology", Ethnomusicology, LVIII/2, pp. 185-221. DOI: 10.5406/ethnomusicology.58.2.0185.

ZBIKOWSKI, LAWRENCE

2010 "Music, Emotion, Analysis", Music Analysis, XXIX/1-2-3, pp. 37-59. DOI: 10.111/ j.1468-2249.2011.00330.x.

ŽIŽEK, SLAVOJ

2003 Ideología, un mapa de la cuestión. México: Fondo de Cultura Económica. 